NBER WORKING PAPER SERIES

\title{
SUBWAYS, STRIKES, AND SLOWDOWNS: \\ THE IMPACTS OF PUBLIC TRANSIT ON TRAFFIC CONGESTION
}

\author{
Michael L. Anderson \\ Working Paper 18757 \\ http://www.nber.org/papers/w18757
NATIONAL BUREAU OF ECONOMIC RESEARCH
1050 Massachusetts Avenue
Cambridge, MA 02138
February 2013

I thank Ken Small, Lowell Taylor, Matt Turner, and participants at the 13th Occasional California Workshop on Environmental and Resource Economics, the 2012 AERE Summer Conference, Texas A\&M, and the University of Houston for valuable suggestions. Any errors in the paper are the author's. The views expressed herein are those of the author and do not necessarily reflect the views of the National Bureau of Economic Research.

NBER working papers are circulated for discussion and comment purposes. They have not been peerreviewed or been subject to the review by the NBER Board of Directors that accompanies official NBER publications.

(C) 2013 by Michael L. Anderson. All rights reserved. Short sections of text, not to exceed two paragraphs, may be quoted without explicit permission provided that full credit, including $\odot$ notice, is given to the source. 
Subways, Strikes, and Slowdowns: The Impacts of Public Transit on Traffic Congestion

Michael L. Anderson

NBER Working Paper No. 18757

February 2013

JEL No. R41,R42,R48

\begin{abstract}
$\underline{\text { ABSTRACT }}$
Public transit accounts for only $1 \%$ of U.S. passenger miles traveled but nevertheless attracts strong public support. Using a simple choice model, we predict that transit riders are likely to be individuals who commute along routes with the most severe roadway delays. These individuals' choices thus have very high marginal impacts on congestion. We test this prediction with data from a sudden strike in 2003 by Los Angeles transit workers. Estimating a regression discontinuity design, we find that average highway delay increases $47 \%$ when transit service ceases. This effect is consistent with our model's predictions and many times larger than earlier estimates, which have generally concluded that public transit provides minimal congestion relief. We find that the net benefits of transit systems appear to be much larger than previously believed.
\end{abstract}

Michael L. Anderson

Department of Agricultural and Resource Economics

207 Giannini Hall, MC 3310

University of California, Berkeley

Berkeley, CA 94720

and NBER

mlanderson@berkeley.edu 


\section{INTRODUCTION}

It is a stylized fact in the transportation literature that mass transit attracts a disproportionate share of public funds but carries a negligible fraction of commuters. In 2010 , public transit received $23 \%$ of federal highway and transit outlays but accounted for $1 \%$ of passenger miles traveled (U.S. Department of Transportation 2009, 2011a, 2011b). State, local, and federal subsidies exceed $\$ 40$ billion per year and cover $63 \%$ of operating costs and 100\% of capital costs. Even in Washington, DC - which boasts the second busiest metro system in the United States - transit accounts for only 5\% of passenger miles traveled (American Public Transportation Association 2011; Schrank, Lomax, and Eisele 2011).

Public transit subsidies nevertheless remain popular in many areas. For example, in 2008 $67 \%$ of Los Angeles County residents voted to allocate $\$ 26$ billion to transit over 30 years. Why is there such deep public support for transit subsidies if few voters are frequent riders? The simplest explanation is the possibility of congestion relief - commuters may expect to benefit from reduced congestion even if they rarely use public transit themselves. ${ }^{1}$ A large body of transportation and economic research, however, concludes that public transit has little effect on reducing congestion, calling into question its heavy subsidy rate (Rubin, Moore, and Lee 1999; Stopher 2004; Small 2005; Winston and Maheshri 2007).

An important detail that has received little attention in the existing literature is that commuters on different roadways in the same metropolitan area face sharply different levels of congestion during peak hours. This paper presents a simple choice model in which commuters face differing levels of congestion and choose either to drive or take transit. Calibrating the model using data from the Los Angeles metro area, we predict effects on congestion that are approximately six times larger than a model that does not account for heterogeneity in congestion levels. This prediction is much larger than previous estimates, and the qualitative conclusion is robust to wide variations in parameter values. The intuition is straightforward: Transit is most attractive to commuters who face the worst congestion, so a disproportionate number of transit riders are commuters who would otherwise have to drive on the most congested roads at the most congested times. Since drivers on heavily congested roads have a much higher marginal impact on congestion than drivers on the average road, transit has a large impact on reducing traffic congestion.

\footnotetext{
1 This possibility is perhaps best summarized by the title of a satirical article in the November 29, 2000, issue of The Onion, "Report: 98 Percent of U.S. Commuters Favor Public Transportation for Others." Other factors that may explain local support of capital investment in transit include high federal matching rates, a combination of concentrated economic rents and dispersed costs, and the political appeal of "ribbon cutting" ceremonies (Taylor 2004; Baum-Snow and Kahn 2005; Winston and Maheshri 2007).
} 
We test our predictions using freeway speed data from a 2003 strike by Los Angeles County Metropolitan Transportation Authority (MTA) workers. In October 2003, MTA workers began a strike that lasted 35 days and shut down MTA bus and rail lines. Using hourly data on traffic speeds for all major Los Angeles freeways, we estimate a regression discontinuity (RD) design using time as the running variable. We find an abrupt increase in average delays of 47\% (0.19 minutes per mile) during peak periods. This increase persists through the end of the strike, and the estimate - consistent with the predictions of our model - is many times larger than estimates in the existing literature. The effects are largest on freeways that parallel transit lines with heavy ridership, and they are small and statistically insignificant during the same period in neighboring counties unaffected by the transit strike.

Our estimates imply that the total congestion relief benefit of operating the Los Angeles transit system is between $\$ 1.2$ billion to $\$ 4.1$ billion per year, or $\$ 1.20$ to $\$ 4.10$ per peak-hour transit passenger mile. We consider the potential gap between the short-run effect of ceasing transit provision (i.e., our estimates) and the long-run effect of a permanent shutdown. We find that reducing the long-run effect to less than $50 \%$ of the short-run effect's lower bound requires implausibly large elasticities of travel with respect to travel costs. We consider the net benefits of constructing the Los Angeles rail system and conclude - contrary to the existing literature on rail capital investment - that they are large and positive.

On a broader scale, our findings demonstrate that in contexts in which policymakers encourage adoption of activities that mitigate negative externalities, considering who adopts the mitigating activity is critical in determining a policy's expected benefits. We close with a brief discussion of other contexts in which selection into mitigating activities may have large impacts on predicted benefits.

\section{BACKGROUND}

Existing economic research on the effects of transit on traffic congestion falls into two categories: model-based estimates and empirical estimates. Examples of the former include Nelson et al. (2007) and Parry and Small (2009). Parry and Small (2009) develop an analytical model of an urban transportation system and compute the optimal transit operating subsidy. The model takes as inputs average speeds, costs, and price and service elasticities. One input is the effect of transit on relieving traffic congestion. They compute this effect using assumptions about substitution between transportation modes and engineering estimates relating average delays and marginal congestion impacts. In Los Angeles, the congestion relief externality of traveling 1 mile on transit during peak hours is computed at 1.7 person- 
minutes of reduced traffic delays. ${ }^{2}$ Aggregating this figure across all peak-period transit passengers implies that transit reduces average delay by approximately 5\% (0.025 minutes per mile). Nelson et al. explore the potential benefits of the Washington, DC transit system using a simulation model in which travel decisions are modeled as a nested logit tree. The model takes as inputs demand response parameters from the literature, and it is calibrated to match aggregate Washington travel patterns. Applying a relationship between traffic flows and traffic speeds similar to that used by Parry and Small, Nelson et al. calculate that the Washington transit system reduces total congestion by 184,000 person-hours per day, or 2.0 person-minutes per peak transit passenger mile carried. This figure is close to the figure implied by Parry and Small.

Researchers employing empirical approaches include Winston and Langer (2006) and Duranton and Turner (2011). Using metropolitan-area data, these authors regress total congestion or vehicle miles traveled (VMT) on measures of transit capacity. They reach varying conclusions. Winston and Langer estimate that rail lines reduce congestion but that bus lines increase congestion. The net effect of transit systems is thus to increase congestion. Duranton and Turner focus on testing the "fundamental law of road congestion" - the hypothesis that the primary determinant of VMT in most cities is roadway capacity. They also estimate a positive relationship between bus fleet size and VMT. To address the potential endogeneity of transit provision, they instrument for bus fleets using an area's 1972 Democratic vote share. The relationship between bus fleets and VMT then becomes statistically insignificant and of variable sign, though the instrument is not powerful enough to rule out the possibility that 1 passenger mile traveled on transit removes substantially more than 1 VMT from roadways. ${ }^{3}$ These findings are nevertheless consistent with our own findings, which suggest that transit has a minimal impact on total VMT but a large impact on

\footnotetext{
${ }^{2}$ In Los Angeles, Parry and Small assume that each passenger mile traveled on transit diverts approximately 0.9 passenger miles from roadways. The average peak period delay in Los Angeles is 0.5 minutes per mile, and estimates from the literature relating traffic flows and traffic speeds suggest that the marginal effect on total delay of adding an additional vehicle to the road is 3.7 times the average delay. The congestion relief externality of traveling 1 mile on transit during peak hours is thus ( -0.9 auto passenger miles/transit passenger mile $* 0.5$ mins avg delay/passenger mile $* 3.7$ mins increased delay $/ \mathrm{min}$ avg delay) $=-1.7 \mathrm{mins}$ increased delay/transit passenger mile.

${ }^{3}$ Duranton and Turner estimate that increasing a city's bus fleet by 18 buses $(10 \%)$ changes annual VMT by $1.3 \%$ to $0.6 \%$ (-35 million to 16 million VMT) in their most precise instrumental variables (IV) specification and $-0.7 \%$ to $4.9 \%$ (-18 million to 133 million VMT) in their least precise IV specification (these figures correspond to $95 \%$ confidence intervals). An average city bus carries 0.3 million passenger miles per year (American Public Transit Association 2011), so adding 5.4 million passenger miles of bus travel could decrease VMT by up to 35 million miles in the most precise specification and up to 18 million miles in the least precise specification.
} 
congestion levels. As we demonstrate below, the type of VMT diverted to transit is critical in determining transit's effects on congestion.

Overall, existing economic research does not support the hypothesis that transit generates large aggregate reductions in traffic congestion. Though transit operating subsidies

may be justifiable on other grounds, such as returns to scale (Parry and Small 2009) or transit passenger welfare gains (Nelson et al. 2007), there is no evidence that transit service is a substantial factor in reducing congestion. At a minimum, the positive externalities appear far too small to justify capital investments in transit infrastructure.

\section{THEORETICAL MODEL}

We begin with a simple choice model in which travelers choose to either drive or take transit. The goal of this model is to explore the quantitative importance of incorporating heterogeneity in observed driving delays. We calibrate the model using data from the Los Angeles metropolitan area. We choose Los Angeles for three reasons. First, it is the location of the transit strike that we use for our RD design. Second, it is one of the three cities included in Parry and Small's comprehensive analysis of optimal transit operating subsidies. Third, its annual transit usage is close to the national urban area average.

\subsection{Theoretical Framework}

Consider an individual who can either drive or take rail transit to her destination (we consider the possibility of bus transit later). For convenience we refer to this individual as a "commuter," though in practice her trip need not be work-related. Commuter $i$ has preferences over consumption of a composite good, $X_{i}$, and generalized commute costs, $T_{i}$. We assume a quasi-linear utility function of the form:

$$
U_{i}=X_{i}-T\left(s_{i}\left(R_{i}\right), a_{i}\left(R_{i}\right), w_{i}\left(R_{i}\right), m\right)
$$

Utility is increasing in the composite good $X$ and decreasing in generalized commute costs $T$. Generalized commute costs are a function of vehicle speed $s_{i}$, access and egress time $a_{i}$, waiting time $w_{i}$, and commute distance $m$. Each of these quantities (except commute distance) is itself a function of whether the commuter takes rail or drives; $R_{i}$ equals one if the commuter takes rail and zero if she drives. The commuter maximizes utility subject to the budget constraint:

$$
\text { s.t. } Y_{i}=X_{i}+m \cdot\left(p_{r} R_{i}+p_{d}\left(1-R_{i}\right)\right)
$$

Income $Y_{i}$ must equal spending on the composite good $X$ (whose price is normalized to unity) plus monetary commute costs. If the commuter takes rail $\left(R_{i}=1\right)$, then commute 
costs are the per-mile cost of rail $\left(p_{r}\right)$ times distance $m$. Otherwise commute costs are the permile cost of driving $\left(p_{d}\right)$ times $m$.

Let the commuter value time at $v_{i}$ dollars per hour. An extensive literature concludes that commuters place a higher value on time spent waiting for transit, stuck in traffic, or walking (Small and Verhoef 2007, p. 53; Abrantes and Wardman 2011) than they do on the same amount of time in other circumstances. Defining a "delay multiplier" $c>1$, we can write the commuter's problem as maximizing:

$$
\begin{gathered}
U_{i}=X_{i}-v_{i}\left[R_{i}\left(\frac{m}{s_{r}}+c\left(a_{r i}+w_{r}\right)\right)+\left(1-R_{i}\right)\left(\frac{m}{s_{d}}+c\left(a_{d}+w_{d i}\right)\right)\right] \\
\text { s.t. } Y_{i}=X_{i}+m \cdot\left(p_{r} R_{i}+p_{d}\left(1-R_{i}\right)\right)
\end{gathered}
$$

where $s_{r}$ is rail speed, $a_{r i}$ is rail access and egress time, $w_{r}$ is average waiting time for the train, $s_{d}$ is free-flow driving speed, $a_{d}$ is car access and egress time, and $w_{d i}$ is driving delay time (i.e., the difference between driving time in free-flow traffic and actual driving time). This leads to a decision rule under which the commuter takes rail if and only if:

$$
\left[c\left(a_{r i}+w_{r}\right)+\frac{m}{s_{r}}\right]-\left[c\left(a_{d}+w_{d i}\right)+\frac{m}{s_{d}}\right] \leq \frac{m}{v_{i}}\left(p_{d}-p_{r}\right)
$$

Rail is the more appealing choice if the difference between delay-penalized rail travel time $c\left(a_{r i}+w_{r}\right)+\frac{m}{s_{r}}$ and delay-penalized driving travel time $c\left(a_{d}+w_{d i}\right)+\frac{m}{s_{d}}$ is less than the difference between the cost of driving and the cost of taking rail, converted from dollars to hours $\left(\frac{m}{v_{i}}\left(p_{d}-p_{r}\right)\right)$. The share of commuters taking rail is thus determined by the probability that the inequality above holds. We calibrate the model under two scenarios. The first scenario assumes that, consistent with the existing literature, all peak-period drivers face the same average congestion delay, $w_{d}$. We set the value of time $v_{i}$ at a fraction of the hourly wage and calibrate the model by varying the distribution of rail access times until the probability of taking rail equals the observed rail market share in Los Angeles. Note that the fraction of rail commuters is determined by the fraction of commuters who live sufficiently close to rail for Equation (1) to hold. If the predicted number of rail commuters is lower than the true number, then we modify the distribution of rail access times to increase the share of commuters who live close to rail. We continue this process until the predicted number of rail commuters matches the actual number.

The second scenario allows for heterogeneous driving delays across commuters. The distribution of congestion delays is set so that the average driving delay is identical to $w_{d}$ in the first scenario, and the model is again calibrated by varying the distribution of rail access 
times until the probability of taking rail equals the observed rail market share. Formally, the two scenarios entail calibrating the following two equations by varying the distribution of rail access times (i.e., $\left.f\left(a_{r i}\right)\right)$ until:

$P\left(R_{i}=1\right)=P\left[c \cdot a_{r i}-\frac{m}{v_{i}}\left(p_{d}-p_{r}\right) \leq c\left(a_{d}+w_{d}-w_{r}\right)+\frac{m}{s_{d}}-\frac{m}{s_{r}}\right] \quad$ (Scenario 1)

$P\left(R_{i}=1\right)=P\left[c\left(a_{r i}-w_{d i}\right)-\frac{m}{v_{i}}\left(p_{d}-p_{r}\right) \leq c\left(a_{d}-w_{r}\right)+\frac{m}{s_{d}}-\frac{m}{s_{r}}\right] \quad$ (Scenario 2)

Of course, buses rather than rail serve many areas. For simplicity, we assume that any given area is served either by buses or by rail but not both. This assumption is reasonable in that the MTA arranges its bus lines so that they do not duplicate the rail service. The commuter takes the bus if and only if:

$$
\left[c\left(a_{b i}+w_{b}\right)+\frac{m}{s_{b i}}\right]-\left[c\left(a_{d}+w_{d i}\right)+\frac{m}{s_{d}}\right] \leq \frac{m}{v_{i}}\left(p_{d}-p_{b}\right)
$$

The decision rule for taking the bus is similar to the rule for taking rail, though with different parameter values. The main difference is that the bus speed $s_{b i}$ varies by commuter. This reflects the fact that buses do not have a dedicated right-of-way and thus may run more slowly on congested routes. We calibrate the bus model under the same two scenarios as the rail model: homogeneous driving delays and heterogeneous driving delays. We assume that everyone who lives more than 1 mile from a rail line (based on the results of calibrating the rail choice model) is in a bus catchment area (i.e., on or near a bus line).

\subsection{Model Calibration}

Table 1 lists the parameter values used to calibrate the rail choice and bus choice models. In cases with any ambiguity we tried to choose parameter values consistent with the previous literature (e.g., Parry and Small 2009). We assume a trip length of 7 miles for commuters in rail catchment areas and 5 miles for commuters in bus catchment areas. Transit headways and fares come from historical MTA documents, and driving costs come from the American Automobile Association (AAA). We could not find authoritative data on parking costs or the share of commuters with free parking, so we assumed that $85 \%$ of commuters have free parking and that parking costs $\$ 5.00$ per day for those with paid parking. These values are roughly consistent with those reported in Willson and Shoup (1990), and our results are robust to variations in these parameters. ${ }^{4}$

${ }^{4}$ Willson and Shoup report that the average market price of parking in Los Angeles Central Business District is $\$ 4.32$ per day and that $91 \%$ of all workers in Los Angeles, Riverside, San Bernardino, and Ventura Counties receive free parking. We view $91 \%$ as an upper bound on the free parking share because the Los Angeles County MTA service area is more densely populated than the counties in Willson and Shoup. 
Of particular importance for the calibration are parameters that vary across individuals: $v_{i}$ and $w_{d i}$. Absent individual heterogeneity, the predicted transit share would be either $0 \%$ or $100 \%$. To set $v_{i}$ we assume that an average commuter values time at half his gross hourly wage and that the elasticity of $v_{i}$ with respect to the wage is 0.8 (Small and Verhoef 2007, p. 52; Parry and Small 2009). This generates a distribution of $v_{i}$ with the $10^{\text {th }}$ percentile at $\$ 4.88$, the median at $\$ 8.76$, and the $90^{\text {th }}$ percentile at $\$ 17.96$. For $w_{d i}$ we assume an average driving delay, relative to the free-flow speed, of 0.5 minutes per mile (Parry and Small 2009). This translates to an average speed of $30 \mathrm{mph}$ when the free-flow speed is $40 \mathrm{mph}$ and $27.1 \mathrm{mph}$ when the free-flow speed is $35 \mathrm{mph} .{ }^{5}$ When $w_{d i}$ varies across commuters, we draw $w_{d i}$ from a gamma distribution parameterized such that the average delay is 0.5 minutes per mile and the right tail is consistent with our freeway speed data in Section 4.2. This implies percentile delays corresponding to the following average speeds: $98^{\text {th }}$ percentile, $13 \mathrm{mph}$; $99^{\text {th }}$ percentile, $11.5 \mathrm{mph}$; $99.9^{\text {th }}$ percentile, $8 \mathrm{mph} .^{6}$ An average speed of $11-12 \mathrm{mph}$ is also consistent with the lowest average speed for a 7-mile trip in Los Angeles that we regularly observed during rush hour in 2012 (Bing Maps 2012). We set bus speeds to strongly correlate with driving speeds $(\rho=0.97)$.

We calibrate the model by varying the distribution of transit access times until the predicted rail and bus shares match their observed values. In Los Angeles, rail and bus account for $0.4 \%$ and $1.2 \%$ of peak-hour travel respectively (Parry and Small 2009). We generate rail access times $a_{r i}$ from a sum of two gamma distributions with shape parameters of 2 (i.e., similar shape to a chi-square with low degrees of freedom). The first gammadistributed random variable, $a_{1 r i}$, represents access time from home to transit. The second, $a_{2 r}$, represents egress time from transit to work. We set $\mathrm{E}\left[a_{2 r}\right]=0.5^{*} \mathrm{E}\left[a_{1 r i}\right]$ to reflect the fact that commercial districts have denser transit service than residential areas. We vary the scale parameter on $f\left(a_{1 r i}\right)$ until predicted rail share equals $0.4 \%$.

\footnotetext{
${ }^{5}$ We use a lower free-flow speed for commuters in bus catchment areas than in rail catchment areas because bus commuters have a shorter average commute. A $40 \mathrm{mph}$ free-flow speed over 7 miles (the rail commute distance) translates to 2.5 miles on local roads at $25 \mathrm{mph}$ and 4.5 miles on freeways at $60 \mathrm{mph}$. A $35 \mathrm{mph}$ freeflow speed over 5 miles (the bus commute distance) translates to 2.5 miles on local roads and 2.5 miles on freeways.

${ }^{6}$ We calculate evening rush-hour median speed for 960 Los Angeles freeway segments when the transit system is operating. The $0.1^{\text {st }}$ percentile speed is $8 \mathrm{mph}$, the $1^{\text {st }}$ percentile speed is $15.5 \mathrm{mph}$, and the $2^{\text {nd }}$ percentile speed is $17 \mathrm{mph}$. We lack speed data for local roads, but Dowling and Skabardonis (2008) take 216 hourly samples across 8 Los Angeles arterial streets and find average speeds between 7 to 10 mph approximately 10\% of the time. Assuming a local road speed of $8 \mathrm{mph}$ for the $0.1^{\text {st }}$ and $1^{\text {st }}$ percentiles and $9 \mathrm{mph}$ for the $2^{\text {nd }}$ percentile, then average trip speeds for the $0.1^{\text {st }}, 1^{\text {st }}$, and $2^{\text {nd }}$ percentiles are approximately $8 \mathrm{mph}, 11.5 \mathrm{mph}$, and $13 \mathrm{mph}$ respectively (as in footnote 5, we assume the 7 mile trip entails 2.5 miles on local roads and 4.5 miles on freeways). Corresponding values for our gamma distribution are $8 \mathrm{mph}, 11.3 \mathrm{mph}$, and $13.2 \mathrm{mph}$. We truncate the distribution at $8 \mathrm{mph}$ to prevent speeds slower than the minimum observed speed in the data.
} 
We generate bus access times $a_{b i}$ from a sum of two triangular distributions. In an area with uniformly distributed population and bus lines placed in a grid pattern, the access time to the nearest bus stop will follow a triangular distribution (see Appendix A1). The first triangular-distributed random variable, $a_{1 b i}$, represents access time from home, and the second triangular-distributed random variable, $a_{2 b}$, represents egress time to work. We again set $\mathrm{E}\left[a_{2 b i}\right]=0.5^{*} \mathrm{E}\left[a_{1 b i}\right]$ and vary the scale parameter on $f\left(a_{1 b i}\right)$ until predicted bus share equals $1.2 \%$. We assume access times $a_{r i}$ and $a_{b i}$ are independent of driving delays $w_{d i}$ and value of time $v_{i}$, but our qualitative results are robust to relaxing this assumption (see Appendix A2). Replacing the triangular distribution with a smoother gamma distribution also has minimal impact on our results (see Appendix A2).

\subsection{Model Results}

Table 2 presents results from calibrating the rail and bus choice models. The first column reports results from a model in which driving delay $w_{d i}$ is fixed at 0.5 minutes per mile for all commuters. All rail and bus passengers would thus face the same $0.5 \mathrm{mins} / \mathrm{mile}$ delay if they were to drive. We compute the effect of ceasing transit service (which would force current rail and bus passengers to drive) by applying a power function of $w_{d}=a$. traffic volume 3.7 (Parry and Small 2009). The predicted effect of ceasing transit service is to increase average driving delays by 0.032 minutes per mile $(6 \%)$. This increase is roughly similar to the effect of transit service on congestion computed by Parry and Small (2009), which is reassuring as their study applied similar parameter values. We also calculate average consumer surplus (relative to driving) and find values of $\$ 0.08 /$ mile for rail passengers and $\$ 0.04 /$ mile for bus passengers.

The second column in Table 2 reports results from a model in which $w_{d i}$ varies across commuters. The average driving delay is 0.5 minutes/mile, but rail and bus passengers come from routes with higher-than-average driving delays. On these routes, if the rail passenger chose to drive instead, the average driving delay would be $3.2 \mathrm{mins} / \mathrm{mile}$. The average driving delay for a bus passenger who drove her own car would be $2.5 \mathrm{mins} / \mathrm{mile}$. As a result, we predict that ceasing transit service would increase average delays by 0.189 minutes per mile $(38 \%)$. This effect is 5.9 times larger than the predicted effect in the homogeneous driving time model, and routes with the most congestion would experience the largest increases. Average consumer surplus (relative to driving) is higher than in the homogeneous 


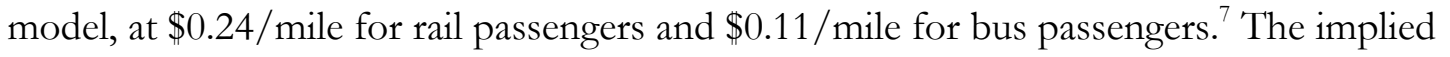
fare elasticity is -1.1 , which is slightly higher than estimates from the literature. ${ }^{8}$

The bottom two rows of Table 2 report the parameter values that calibrate the model in each case. We calibrate the model using transit access times; comparing the calibrated access time distribution to the true access time distribution serves as a check on the model. In reality, approximately $26 \%$ of the Los Angeles metropolitan area lives within 2 miles of a rail line, and the spacing between bus lines in residential areas is generally between 0.5 and 0.75 miles. $^{9}$ When calibrating the homogeneous model, $51 \%$ of commuters live within 2 miles of a rail line, and the implied spacing between bus lines is 0.4 miles. When calibrating the heterogeneous model, $30 \%$ of commuters live within 2 miles of a rail line, and the implied spacing between bus lines is 0.5 miles. The parameter values that calibrate the heterogeneous driving time model are thus reasonably close to their true values.

The intuition underlying our results is straightforward. Driving is the more attractive option for most commuters because the average cost of driving (including the cost of time) is much lower than the average cost of transit. Nevertheless, some commuters choose transit, and these commuters must be different from the average commuter along one or more dimensions. An important dimension is transit access time - commuters who choose transit tend to live close to transit. Another dimension is roadway congestion - commuters who choose transit tend to commute on highly congested routes. As long as there is substantial heterogeneity in traffic delays, commuters choosing transit will come from routes that have higher than average congestion. This implies that their marginal effect on congestion will be higher than the average commuter's marginal effect on congestion, and the model demonstrates that the difference is potentially very large.

The qualitative result that a model with heterogeneous driving times predicts much larger effects from ceasing transit service than a model with homogeneous driving times is robust to a wide range of parameter values. In general, assumptions that lower the cost of driving or increase the cost of transit service will widen the difference between the two

\footnotetext{
${ }^{7}$ These values represent average consumer surplus for rail (bus) passengers at current congestion levels. If a significant number of rail (bus) passengers drove instead, increasing congestion, then average consumer surplus among the remaining passengers would likely increase.

${ }^{8}$ Litman (2004) summarizes long-run fare elasticity estimates as ranging from -0.6 to -0.9 . Our overall fare elasticity of -1.1 is driven by a fare elasticity of -1.3 for bus riders. This elasticity of -1.3 is likely too large because we do not consider "captive" bus riders who do not own cars. However, we show in Appendix A2 that the qualitative conclusions from our model are robust to introducing captive bus riders.

${ }^{9}$ In 2003, approximately 240 square miles of Los Angeles were within two miles of a subway or light rail line. The average population density of zip codes containing rail lines is 13,648 residents per square mile (author's calculation from US Census). Thus 3.3 million of the 12.8 million Los Angeles metropolitan area residents $(26 \%)$ lived within two miles of a rail line.
} 
models' predictions. ${ }^{10}$ In cases with uncertainty we therefore err on the side of picking high values for driving costs and low values for transit costs. For example, we assume that drivers account for all vehicle operating costs (gas, maintenance, and tires) rather than only gas costs, and we assume that transit riders are risk-neutral with respect to waiting time for the bus or train (i.e., they only care about expected waiting time, not the variance in waiting time).

In some cases the parameter choices do not have clear implications for the relative cost of driving versus transit. Specific examples include the delay multiplier (which applies to both driving delays and transit wait and access time), the wage multiplier, and trip length. We test the sensitivity of our conclusions to reasonable variations in these parameters and to the addition of a group of riders who are "captive" to transit because they do not own cars. In all cases the model with drive time heterogeneity predicts qualitatively larger congestion impacts from ceasing transit than the model with homogeneous drive times. Nevertheless, the magnitudes vary substantially. For example, the predicted congestion impacts from the heterogeneous model are 3.4 times larger than the homogeneous model if we reduce the delay multiplier from $c=1.8$ to $c=1.3$, but they are 7.7 times larger if we increase the delay multiplier to $c=2.3$. There is also some sensitivity to trip length and the wage multiplier (see Appendix A2). Augmenting the model with a group of commuters who do not own cars and thus always take the bus attenuates the overall effect of ceasing transit service but has little impact on the relative magnitudes of the homogeneous and heterogeneous models' predictions (the latter is 6.1 times larger than the former). Incorporating the possibility that access times are lower when delays are higher (i.e., when transit lines are located in dense, congested areas) slightly increases the predicted effect of ceasing transit service, and incorporating the possibility that lower-income households locate near transit lines modestly decreases it (see Appendix A2). Thus, while our model unambiguously predicts much larger congestion impacts from ceasing transit service than the previous literature, it does not identify exact magnitudes. For this we turn to empirical estimates.

\section{REgRESSION DISCONTINUITY ESTIMATES}

On October 14, 2003, Los Angeles County MTA workers went on strike, shutting down the entire transit system for 35 days. We use this abrupt halt in service to estimate the effects of transit provision on traffic congestion. To do so we implement an RD design with the date as the running variable and October 14 as the discontinuity threshold. This design is

\footnotetext{
${ }^{10}$ As the average cost gap between driving and transit increases, commuters need more extreme shocks in order to choose transit. This means that transit commuters either need to live very close to transit or need to experience more severe driving delays. The latter factor increases their marginal impact on congestion.
} 
similar in principle to the RD designs implemented by Davis (2008), Auffhammer and Kellogg (2011), Chen and Whalley (2012), and Bento et al. (2012).

\subsection{Institutional Background}

The Los Angeles County MTA provides heavy rail (subway), light rail, and bus service for approximately 10 million people in a 1,400 square mile service area. The MTA service area includes most incorporated areas in Los Angeles County; the largest populated area that is not served by the MTA is the area east of I-605 (basically the area from El Monte to Pomona). In 2003 it operated one subway line (the Red Line), two light rail lines (the Blue and Green Lines), and dozens of bus lines. ${ }^{11}$ The bus lines included five "Metro Rapid" lines featuring frequent service, limited stops, and traffic signal preemption (the number of Metro Rapid lines has since increased). The busiest Metro Rapid line - the Rapid 720 - runs down Wilshire Boulevard and carries more passengers than the Metro Green light rail line. The average number of weekday passenger boardings was 200,000 on all three rail lines and 1.1 million on all bus lines. While the MTA is by far the largest transit provider in Los Angeles County, some municipalities complement MTA service with their own bus lines, primarily to fill gaps in local intra-municipality service. Metrolink commuter rail service is also operated independently of the MTA and serves a much larger geographic area (the majority of its track lies outside Los Angeles County). Overall, annual transit usage in the Los Angeles area is very close to the national urban area average (244 miles travelled per capita in Los Angeles versus 252 miles travelled per capita nationwide; Schrank, Lomax, and Eisele 2011).

Private automobiles account for over $98 \%$ of passenger miles traveled in the Los Angeles metropolitan area. Fifty-three percent of VMT occur on freeways, with the remainder on city streets. Congestion levels in Los Angeles average 0.34 minutes of delay per VMT (peak and off-peak), which is higher than the national urban area average of 0.21 minutes per VMT but closer to the average level in other large urban areas of 0.28 minutes per VMT (all figures are from Schrank, Lomax, and Eisele 2011). ${ }^{12}$ The backbone of the Los Angeles freeway network contains three freeways running northwest-to-southeast (I-5, US101, and I-405), two freeways running east-west (I-10 and I-105), and two freeways running north-south (I-110 and I-710). Several smaller state freeways (SR-2, SR-60, SR-91, and SR170) supplement these primary freeways. Ramp meters regulate traffic flows at most freeway

\footnotetext{
${ }^{11}$ A third light rail line, the Gold Line, began operation three months before the strike, but it had not attracted significant ridership by the time of the strike.

12 Other large urban areas include Atlanta, Boston, Chicago, Dallas-Fort Worth, Detroit, Houston, Miami, Philadelphia, Phoenix, San Diego, San Francisco-Oakland, Seattle, and Washington, DC. We exclude New York-Newark from this category because of its unique attributes, particularly with respect to transit use.
} 
entrances, and many freeways contain carpool lanes. Figure 1 covers the MTA service area and shows the major Los Angeles highways and MTA rail lines.

The 2003 strike was rooted in a disagreement by MTA mechanics over contributions to a health care fund. The mechanics had worked without a contract for over one year before striking on October 14. The strike's exact timing was exogenous in that it occurred on the first business day following the expiration of a 60-day court-ordered injunction on striking. MTA drivers, clerks, and supervisors honored the mechanics' picket line, shutting down the entire system (Streeter and Bernstein 2003). A small number of contract-operated MTA bus lines continued service, and the MTA contracted a "Red Line Special" bus service to duplicate part of the Red Line subway route. Metrolink also continued scheduled commuter rail service. However, these combined services carried an insignificant fraction of total MTA riders. Anecdotal evidence suggested that congestion increased substantially during the strike (Rubin 2003), and this was later confirmed in data analyses. ${ }^{13}$ The strike continued until November 18, at which point service was gradually resumed over the following week (Streeter, Bernstein, and Liu 2003).

\subsection{Data}

The data for our study come from the Caltrans Performance Measurement System (PeMS). All major divided freeways in California contain embedded loop detectors that continually measure the number of vehicles crossing the detector and the average time that each vehicle spends over the detector. Using these data, PeMS constructs hourly measures of vehicle flows and average vehicle speed for each detector. The average spacing between loop detectors is 0.6 miles along the freeways in our sample.

The primary outcome is average delay, measured in minutes per mile. We assume a free-flow speed of $60 \mathrm{mph}$ on freeways (Schrank and Lomax 2003) and calculate delay as $(60 /$ speed -1$)$, with a lower bound of 0 . For example, a speed of $40 \mathrm{mph}$ corresponds to a

\footnotetext{
13 The Los Angeles Department of Transportation reported that the number of cars and trucks on the road increased 4\% during the strike (Bernstein, Pierson, and Hernandez 2003). Lo and Hall (2006) analyzed average traffic speeds from 7:00 a.m. to 8:00 a.m. and focused on three highways paralleling MTA rail lines (US-101, I105, and I-110). Doing a simple before-and-after comparison, they found that average traffic speeds declined between 0 and $37 \%$ on these highway segments. In contrast to Lo and Hall, we analyze all loop detectors on all major Los Angeles highways during all peak hours. We employ a regression discontinuity design, which turns out to be important for achieving identification in this context. If we replicate Lo and Hall's before-and-after design on "control" freeways in neighboring counties, we find that peak-period delays increased 32.3\% $(t=7.0)$ during the strike. These highways were too far from Los Angeles County to be affected by the strike, so seasonal trends or other unobserved factors must be driving the observed increase. Estimating the RD design on the same control freeways generates estimates that are much smaller (e.g., 11.7\%) and statistically insignificant (see Section 4.5).
} 
delay of 0.5 minutes per mile. Our results are robust to alternative values for free-flow speed (e.g., $65 \mathrm{mph}$ or $55 \mathrm{mph}$ ) or to using average speed itself as the dependent variable.

We focus on weekday peak hours since this is when congestion occurs. We define peak hours as hours during which the average speed on Los Angeles freeways consistently fell below $60 \mathrm{mph}$ during the pre-strike period. Under this definition, the morning peak lasts from 7 a.m. to 10 a.m., and the evening peak from 2 p.m. to 8 p.m. We prefer a broad definition of peak hours because the strike lengthens the morning and evening commute periods. Shortening the peak period increases the average level of congestion and the magnitude of our estimates. We exclude weekends and holidays from our data set.

Table 3 reports summary statistics for our data set over a 200-day window containing the strike. Each observation is a detector-by-hour. The first two columns report unweighted means and standard deviations, and the last two columns report VMT-weighted means and standard deviations. For average speed, average delay, and share of time occupied, the VMT weight equals the length of highway covered by a detector multiplied by the average prestrike traffic flow across the detector. ${ }^{14}$

The average highway is 3.2 lanes wide and carries approximately 4,400 vehicles per hour (in each direction). Average speed is $52.8 \mathrm{mph}$ when the strike is not in effect and drops to $48.3 \mathrm{mph}$ during the strike; average delays increase accordingly. Peak vehicle flows are 1\% lower during the strike, in part because increased congestion reduces roadway capacity. Detectors are occupied by vehicles $11 \%$ of the time outside the strike and $12.5 \%$ of the time during the strike. The number of detectors changes slightly over time because detectors go in and out of service. We include detector fixed effects in our specifications to ensure that changes in the composition of detectors in service do not bias our estimates.

\subsection{Regression Discontinuity (RD) Specification}

We use an RD design to estimate the effects of the transit strike. Specifically, we estimate the equation:

$$
y_{i t}=\alpha+\beta \text { strike }_{i t}+\gamma f\left(\text { date }_{i t}\right)+\varepsilon_{i t}
$$

In this equation $y_{i t}$ is the average delay (in minutes per mile) for detector $i$ during hour $t$, strike $e_{i t}$ is a binary variable equal to unity when the strike is in effect and zero otherwise, and date $_{i t}$ is the date measured in days from the beginning of the strike. Identification in the RD model comes from assuming that the underlying, potentially endogenous relationship between $\varepsilon_{i t}$ and the date is fully captured by the flexible function $f($.$) . In particular, the$

${ }^{14}$ For lanes and total flow, the weight equals the length of freeway covered by a detector, and for average share of time occupied the weight equals the length of freeway covered by a detector times the number of lanes. 
relationship between $\varepsilon_{i t}$ and the date must not change discontinuously on or near the date on which the strike begins. The RD is a sharp RD in that the running variable date ${ }_{i t}$ completely determines strike $e_{i t}$.We set the RD threshold at the beginning of the strike rather than the end of the strike because service is restored gradually when the strike ends. There is thus no sharp change in the "treatment" when the strike ends.

To estimate this model we follow Imbens and Lemieux (2008). With date $_{i t}$ normalized to be zero on the day the strike begins, we estimate local linear regressions of the form:

$y_{i t}=\alpha+\beta$ strike $_{i t}+\gamma_{1}$ date $_{i t}+\gamma_{2}$ date $_{i t} \cdot$ strike $_{i t}+\delta \mathbf{X}_{\mathbf{i t}}+\varepsilon_{i t}$

The terms date $_{i t}$ and date $_{i t}$ strike $_{i t}$ should absorb any smooth relationship between the date and $\varepsilon_{i t}$ If the RD assumption is valid (i.e., $\varepsilon_{i t}$ does not change discontinuously when the strike begins) our estimate of $\beta$ will be unbiased even without the additional controls $X_{i t}$. However, we include several variables in $X_{i t}$ to increase the precision of our estimates. These additional controls include day-of-week indicators and detector fixed effects. ${ }^{15}$ In our base specification we use a bandwidth of 28 days on each side of the threshold. The strike began on October 14, 2003, so the sample includes dates between September 16 and November 10 (excluding all weekends and holidays). In alternative specifications we use varying bandwidths and find similar results. In all cases we weight each detector by pre-strike VMT. In practice this means each observation is weighted by $\omega_{i}$, which equals the length of highway covered by detector $i$ multiplied by the average traffic flow across detector $i$ in the pre-strike period. Unweighted regressions generate qualitatively similar results.

Statistical inference is complicated by the fact that $\varepsilon_{i t}$ is correlated both over time and across detectors. It is thus impossible to construct a single set of clusters in which observations in different clusters are independent of each other. We address this problem by clustering along both the day and the detector dimensions, as suggested in Cameron, Gelbach, and Miller (2011). The resulting standard errors are robust both to within-day and within-detector serial correlation.

\subsection{RD Results}

Figure 2 plots the average delay by week across all major Los Angeles freeways for a 28-week window containing the strike. Each point is a VMT-weighted average of delays during peak periods across all detectors. Some weeks are missing one or more weekdays due

${ }^{15}$ Dropping $X_{i t}$ increases the standard errors somewhat but has little impact on the estimates of $\beta$. 
to holidays. To adjust for this we plot the residuals from a regression of average delay on day-of-week indicators rather than plotting the raw average delay. The two dashed lines in the figure indicate the beginning and the end of the strike. Delays average around 0.4 minutes per mile in the 12 weeks leading up to the strike and then jump discontinuously to 0.6 minutes per mile during the strike. Average delay increases as the strike continues, suggesting that the strike's impacts are not confined to the initial week of the strike. Delays fall following the strike but take several weeks to reach pre-strike levels. There are several reasons for this gradual decline. First, service is slowly phased back in over the first week following the strike. Second, the weeks around Thanksgiving (which occurs two weeks after the strike ends) tend to have higher-than-average delays (see Section 4.5). Finally, it may take commuters some time to readjust to their original travel patterns. The outlier at week 24 is the week containing New Year's Day.

Figure 3 plots the average delay by week for freeways that parallel major transit lines. The four busiest transit lines in 2003 were the Red Line (99,000 daily boardings), the Blue Line (67,000 daily boardings), the Green Line (32,000 daily boardings), and the Metro Rapid 720 bus line (45,000 daily boardings). Panels A and B in Figure 3 plot the average delay on US 101 and Interstate 105. US 101 parallels the Red Line subway, and Interstate 105 contains the Green Line on its median. In both cases there is a striking and sustained increase in average delay after the strike begins. Panels $C$ and D plot average delay on Interstates 110 and 710 and on Interstate 10. Interstates 110 and 710 parallel the Blue Line, though both of them lie 2 to 4 miles away from the line itself. Interstate 10 parallels the Metro Rapid 720 bus line. In both panels there is a notable increase in average delay after the strike begins, though it is less dramatic than on US 101 or Interstate 105.

Table 4 presents the regression analogs of Figures 2 and 3. Each column reports results from a separate regression. The first column estimates Equation (2) on a sample that includes all major Los Angeles freeways. The average delay increases by 0.19 minutes per mile $(t=4.7)$, or $47 \%$ of the pre-strike average delay. The second column reports results for US 101. Average delay increases by 0.33 minutes per mile $(t=4.4)$, or $90 \%$ of the pre-strike average. Columns (3), (4), and (5) report results for Interstate 105, Interstates 110 and 710, and Interstate 10 respectively. Average delay increases between 53\% and $81 \%$ when the strike begins, and the coefficients are significant in all three columns. Column (6) reports results for all major Los Angeles freeways that do not parallel a major transit line. Average delay increases by 0.13 minutes per mile $(29 \%)$ on these freeways when the strike begins. 
The increase is statistically significant $(t=3.0)$, but it is more modest than the increases observed on freeways paralleling major transit lines.

Table 5 presents regression estimates for the a.m. peak period only. Column (1) reports results for all major Los Angeles freeways. Average delay increases by 0.31 minutes per mile $(67 \%)$ when the strike begins $(t=4.2)$. Columns (2) through (5) report a.m. peak period results for freeways that parallel major transit lines. Morning delays increase 123\% and 106\% on freeways that parallel the Red Line and Green Line respectively. They increase $39 \%$ on freeways paralleling the Blue Line and $65 \%$ on the freeway paralleling the Rapid 720 bus line. Morning delays on freeways not paralleling major transit lines, reported in Column (6), increase $56 \%$. All estimates in Table 5 are statistically significant.

Table 6 reports analogous estimates for the p.m. peak period. Average delay increases 0.16 minutes per mile $(41 \%)$ across all major freeways $(t=3.9)$. Delays are again concentrated on freeways that parallel major transit lines. Average delay on these highways, reported in Columns (2) through (5), increases between 66\% and 78\%. The coefficients are smaller in magnitude than during the a.m. peak period. This occurs in part because the p.m. peak period is longer, with lower average delay. Transit may also be a poorer substitute for driving during evening because some trips involve returning late at night, when trains and buses run less frequently. The increase in average delay on freeways that do not parallel major transit lines, reported in Column (6), is statistically insignificant.

Table 7 presents regressions measuring the strike's effect on freeway occupancy. The dependent variable in these regressions is the share of time that a detector is occupied. This share increases with the density of cars on the roadway. If cars were placed bumper-tobumper, the share of time occupied would be $100 \%$. If the average space between cars were equal to the average length of a car, the share of time occupied would be $50 \%$. The first column reports results for all major Los Angeles freeways during peak hours. The share of time occupied increases 1.3 percentage points $(t=4.1)$, or $12 \%$ of the pre-strike level. Columns (2) through (5) report larger increases of 1.6 to 2.3 percentage points on freeways paralleling major transit lines. The increase in share of time occupied on other freeways, reported in Column (6), is 0.8 percentage points $(t=2.5)$.

A $12 \%$ increase in the share of time occupied does not imply that the total number of vehicles traveling on freeways increased $12 \%$. This distinction arises because the share of time occupied is a function of both the number of vehicles on the freeway and the speed at which they travel. If the density of vehicles were homogeneous over time, then speed would not affect the share of time occupied; a decrease in speed would have the same 
proportionate impact on the time a vehicle takes to cross the detector and the time it takes for the next vehicle to reach the detector. However, the density of vehicles is heterogeneous over time, and the share of time occupied is a weighted average of different vehicle densities, with weights inversely proportional to speed. ${ }^{16} \mathrm{~A} 1 \%$ increase in vehicles thus increases the share of time occupied by more than 1\% because it both increases vehicle density and increases the relative weight placed on higher levels of density (recall that a vehicle's marginal effect on congestion is strongly increasing in average congestion). The increase in share of time occupied will be particularly high if, as predicted by our model, the increase in vehicles is concentrated among times and freeways with the highest vehicle densities.

Table 8 presents estimates of the strike's effect on peak-hour vehicle flows. The dependent variable is the hourly traffic flow per lane. The first column reports results for all major Los Angeles freeways. Vehicle flows fall by 31 cars per hour $(t=3.2)$ during peak hours, or $2.2 \%$ of pre-strike levels. The effects are particularly strong on the freeways paralleling the Red Line and the Rapid 720 (Columns (2) and (5)), but statistically insignificant on freeways paralleling the Green and Blue lines (Columns (3) and (4)). It may seem counterintuitive that vehicle flows decrease when transit shuts down, but this occurs because traffic throughput decreases as congestion increases (Small and Verhoef 2007). Thus, while the density of vehicles on the freeways increases, the number of vehicles crossing a specific point per hour decreases. If we estimate the regression in Column (1) using all hours of the day, we find a statistically insignificant effect of the strike on total vehicle flows. The $95 \%$ confidence interval ranges from -13.7 to +9.8 vehicles per hour, or $-1.3 \%$ to $+1.0 \%$ of pre-strike levels (see Appendix Table A3). These results are consistent with our model, which predicts small changes in VMT but large changes in average delays, and with the fact that the MTA transports less than $2 \%$ of the region's total passenger miles. However, we cannot rule out larger changes in VMT on arterial roads as freeways slow down.

\subsection{Falsification Tests}

Identification in the RD model comes from assuming that the conditional expectation $\mathrm{E}\left[\varepsilon_{i t} \mid\right.$ date $\left._{i t}\right]$ is smooth as date $_{i t}$ crosses the RD threshold. In our context this implies that factors affecting traffic congestion must not change sharply on or near October 14, 2003.

\footnotetext{
${ }^{16}$ Consider a set of vehicle platoons of heterogeneous density $x$ crossing detector $i$. The density measure $x$ runs from 0 (a platoon with no vehicles) to 1 (a platoon that is bumper-to-bumper). Let $f(x)$ represent the frequency at which platoons of density $x$ occupy detector $i$. The average share of time occupied for detector $i$ is $\int_{0}^{1} x f(x) d x$. However, $f(x)=($ minutes taken for platoons of density $x$ to cross detector $i) / 60$ minutes $=[($ length of platoons of density $x$ in miles $) /($ speed of platoons of density $x$ in miles per minute $)] / 60$ minutes $=$ (length of platoons of density $x$ in miles) $/\left[60^{*}\right.$ (speed of platoons of density $x$ in miles per minute) $]$. The weighting function $f(x)$ is thus inversely proportional to the speed at which platoons of density $x$ travel.
} 
The exact timing of the strike corresponded to the expiration of a 60-day court injunction and is thus exogenous. Nevertheless, it is important to rule out any possibility of seasonal effects influencing our results, particularly since the strike began the first day following a three-day weekend (Columbus Day weekend).

We conduct two falsification tests to rule out bias in our RD design. First, we estimate the strike's effect on traffic in neighboring Orange and Ventura counties. Portions of these counties lie within the Los Angeles Combined Statistical Area, but neither county lies within the Los Angeles MTA's service area. We focus on sections of US 101 in Ventura County and I-5 and I-405 in Orange County that lie near the Los Angeles County border. However, to avoid spillover effects we exclude any portions of the freeways that are within 10 miles of the MTA service area. If the RD design is valid, then there should be no statistically significant effects on these "control" freeways.

Figure 4 plots average delay by week on the control freeways. There is no significant break in average delay when the strike begins. Table 9 presents the regression analog of Figure 4. The first three columns report results from estimating Equation (2) on the control highways. Column (1) uses data from both morning and evening peak hours. Average delay increases by a statistically insignificant 0.02 minutes per mile (12\% of the pre-strike level). Columns (2) and (3) present results from the morning and evening peak hours. In both columns the increase is statistically insignificant and less than $15 \%$ of pre-strike levels.

Our second falsification test examines delays on Los Angeles freeways one year after the strike. If seasonal effects drive our results, then similar discontinuities should appear one year later. We code a "placebo" strike that begins October 12, 2004 - the day after Columbus Day - and lasts 35 days (the length of the real strike). Since there was no strike during this period, we expect to find no significant effects if our research design is valid.

Figure 5 plots average delays on major Los Angeles freeways during the weeks surrounding the 2004 placebo strike. There is no visually perceptible break at the beginning of the placebo strike. However, delays trend upwards in the weeks during and directly after the placebo strike, suggesting that traffic increases in the weeks approaching Thanksgiving even absent a strike. The fourth column of Table 9 presents the regression analog of Figure 5. It estimates Equation (2) using data within 28 days of October 12, 2004. Average delay during peak hours increases a statistically insignificant 0.06 minutes per mile (14\% of "prestrike" levels). Columns (5) and (6) estimate the same regression using only morning and evening peak period data respectively. In both cases the changes are statistically insignificant and represent less than $15 \%$ of "pre-strike" levels. 


\section{Discussion}

The RD results demonstrate that ceasing public transit service causes a marked increase in traffic delays. Our model calibration results predict a 0.189 minutes per mile $(38 \%)$ increase in average delay (Table 2). In comparison, our preferred RD estimate (Column (1) of Table 4) finds that average delay increases 0.194 minutes per mile (47\%). The observed absolute change is similar to our model's prediction, but the proportional change is larger. The discrepancy in the proportional change occurs because we observe an average pre-strike delay of 0.41 minutes per mile instead of the reported Los Angeles average of 0.5 minutes per mile. Part of this difference may arise because we only have data on freeway delays and do not observe delays on arterial roads (the 0.5 minutes per mile figure averages delays across freeways and arterial roads). Regardless, the RD estimates come much closer to matching the predictions of the model with heterogeneous driving delays than they do to matching the predictions of the model with homogeneous driving delays.

\subsection{Potential Congestion Relief Benefits}

How large are the congestion relief benefits of public transit? We calculate these benefits under two scenarios. Our first scenario focuses on the reduction in freeway delays, which is all we can observe in our data. Los Angeles freeways carry approximately 36 billion passenger miles of peak-hour travel each year (Parry and Small 2009; Schrank, Lomax, and Eisele 2011). An increase of 0.19 minutes per mile in average delay therefore implies an aggregate increase of 114 million hours of delay per year. Valuing time at half the average hourly wage, or $\$ 10.30$, we estimate an annual congestion relief benefit of $\$ 1.2$ billion per year (U.S. Department of Labor 2004). However, motorists appear to place a higher value on time spent stuck in traffic than on time spent driving on uncongested roads. If we apply a delay multiplier of 1.8 , the annual congestion relief benefit becomes $\$ 2.1$ billion. These estimates represent a lower bound on the congestion relief benefits since they assume that transit has no effect on arterial road congestion.

In the second scenario we assume that ceasing transit service increases delays on arterial roads by the same amount that it increases delays on freeways. This assumption may underestimate or overestimate transit's true effects, but there are strong reasons to believe that congestion on arterial roads increased as much as or more than on freeways. In particular, ramp meters restrict vehicle flows onto Los Angeles freeways, but they are not used on arterial roads. Los Angeles freeways and roadways combined carry approximately 70 billion passenger miles of peak-hour travel each year (Parry and Small 2009). A 0.19 minutes per mile increase in average delay thus increases aggregate delays by 222 million hours per 
year. The annual congestion relief benefit is $\$ 2.3$ billion when valuing time at half the hourly wage and $\$ 4.1$ billion when applying a delay multiplier of 1.8 .

We can also express the congestion relief benefit in "per transit passenger mile" terms. The Los Angeles MTA carried approximately 1 billion passenger miles during peak hours in 2003. A lower bound on the congestion relief benefit per peak-hour transit passenger mile is thus $\$ 1.20$ ( $\$ 1.2$ billion/1 billion passenger miles), and reasonable estimates are as high as $\$ 4.10$ per peak-hour transit passenger mile ( $\$ 4.1$ billion/1 billion passenger miles). These estimates are many times larger than those in the previous literature. For example, a 0.025 minutes per mile increase in average delay - which is consistent with Parry and Small's calculations - would imply a congestion relief benefit of between $\$ 0.16$ to $\$ 0.54$ per peakhour transit passenger mile. ${ }^{17}$ The congestion relief benefit is also much larger than estimates of consumer surplus. For example, the results in Table 2 from our choice model suggest average consumer surplus of $\$ 0.24 /$ mile for peak rail passengers and $\$ 0.11 /$ mile for peak bus passengers. The congestion relief benefits thus appear to be an order of magnitude larger than the private benefits to transit riders (at least for those riders that own cars).

A final external benefit that we consider is agglomeration externalities. Several studies suggest that increasing traffic speeds raises productivity by reducing "effective distance" (Prud'homme and Lee 1999; Graham 2007). These papers conclude that a 10\% increase in commuting speed raises productivity by $2-3 \%$. In our context this suggests that the transit system might increase productivity by $\$ 400-600$ million per year, or $\$ 0.40-0.60$ per peakhour passenger mile. ${ }^{18}$ These benefits appear larger than our consumer surplus estimates.

\subsection{Long-Run Implications}

In the long run, individuals may adapt to increased traffic congestion costs using strategies that are not feasible in the short-to-medium run. Indeed, the "fundamental law of road congestion" implies that in the long run individuals respond to increases in congestion by reducing travel to some degree. The long-run effect on congestion of permanently eliminating public transit may therefore be smaller than the short-run effect of temporarily shutting down public transit. Potential long-run adaptations that may not be available in the short run include increasing telecommuting, ride sharing, moving closer to work or school,

\footnotetext{
17 The $\$ 0.16$ value applies if we limit delays to freeways only and apply no delay multiplier. The $\$ 0.54$ value applies if we assume delays occur on all roads and apply a delay multiplier of 1.8.

18 We calculate this figure as: 395,000 Downtown LA workers $\times \$ 43,200$ average salary $\times 12 \%$ speed increase $\times 2-3 \%$ productivity increase per 10\% speed increase $=\$ 410-614$ million. Employment figures are from Thornberg and Haveman (2010).
} 
and leaving the metropolitan area entirely. The first three represent reductions in travel demand, while the fourth represents a relocation of travel demand.

To evaluate the potential long-run reduction in travel demand due to increased congestion, we draw on two literatures. The first links gas prices and travel demand, and the second links congestion charges and travel demand. Like an increase in gas prices or a congestion charge, an increase in road congestion raises the cost of travel. In all cases we expect travel demand to fall as a result. Small and van Dender (2007) estimate average longrun VMT elasticities with respect to fuel cost ranging from -0.11 to -0.22 . Bento et al. (2009) estimate a long-run VMT elasticity with respect to gas prices of -0.34, and Knittel and Sandler (2011) estimate an average "two-year" elasticity of miles traveled with respect to gas prices of -0.26 . We thus consider a "low" estimate of -0.15 for the long-run VMT elasticity with respect to fuel cost (Small and van Dender's estimate using 2006 gas prices) and a "high" estimate of -0.34 for the long-run VMT elasticity. These elasticities imply longrun VMT elasticities with respect to total travel costs (i.e., fuel costs plus time costs) of -0.67 in the "low" case and -1.5 in the "high" case. ${ }^{19}$ We supplement these estimates with estimates of the long-run ( 5 year) travel demand response to the London congestion charge, which imply a VMT elasticity with respect to total travel costs of -2.0 (Evans 2008, p. 5). ${ }^{20}$ We consider this the "extreme" case because London has world-class metro and bus systems, which should make roadway travel demand more elastic. In contrast, our counterfactual simulation posits a Los Angeles metro area with no transit service at all.

We solve for a long-run equilibrium using a VMT demand equation of $Q_{d}=b$. (time cost + fuel cost $)^{-\eta}$, with $\eta=0.67$ in the low case, $\eta=1.5$ in the high case, and $\eta=$ 2.0 in the extreme case. The "supply" equation relating VMT and travel delays is given by the power function delay $=a \cdot Q_{S}^{3.7}$ (see Section 3.3). ${ }^{21}$

Panel A of Table 10 summarizes the travel demand response and corresponding longrun congestion-relief effects under different long-run VMT elasticities. Under a long-run VMT elasticity with respect to total travel costs of -0.67 , long-run travel demand falls

\footnotetext{
${ }^{19}$ Delay-penalized time costs are approximately $240 \%$ higher than fuel costs.

${ }^{20}$ Evans finds a long-run VMT elasticity with respect to total travel costs of -1.9 to -2.1 when using a value of time of $f^{10.8 / \mathrm{hr}}(\$ 16.60 / \mathrm{hr})$.

${ }^{21}$ We use the supply and demand equations to solve for equilibrium values at which $Q_{d}=Q_{s}$. Quantities are normalized to one during the period before the strike, and the parameters $a$ and $b$ are determined by the average delays observed prior to the strike. The shift in demand following the strike, which represents a change in $b$, is calculated by finding the value of $b$ that satisfies the short-run equilibrium at which $Q_{d}=Q_{s}$ during the strike. To solve for this equilibrium we apply short-run VMT elasticities of $\eta=0.14$ in the low case, $\eta=0.37$ in the high case, and $\eta=0.50$ in the extreme case (Small and van Dender 2007). A spreadsheet detailing these calculations is available from the author.
} 
between $2.5 \%$ (on lightly affected freeways) to $6.7 \%$ (on heavily affected freeways). The demand reduction is modest for two reasons. First, even on heavily affected freeways, the short-run increase in congestion costs represents only a $21 \%$ increase in total travel costs. Second, these are long-run equilibrium values, and in the long run congestion does not increase as much as in the short run. With these reductions the long-run effect on delays is between $56 \%$ of the short-run effect (on heavily affected freeways) to $63 \%$ of the short-run effect (on lightly affected freeways). If we increase the long-run VMT elasticity to -1.5 (the "high" case), then the long-run effect on delays ranges from $45 \%$ to $51 \%$ of the short-run effect. In the "extreme" case of a VMT elasticity of -2.0, the long-run effect is between $40 \%$ to $46 \%$ of the short-run effect. All of these calculations apply a delay multiplier of 1.8 and assume that transit's effect on arterial congestion is similar to its effect on freeway congestion. Panel B applies no delay multiplier - which is necessary for calculating the lower bound on the congestion relief benefit (see Section 5.1) - and assumes no arterial congestion. The long-run effect on delays is now $85 \%$ of the short-run effect if $\eta=0.67,79 \%$ of the short-run effect if $\eta=1.5$, and $75 \%$ of the short-run effect if $\eta=2.0 .^{22}$ The lower bound on the long-run benefit is thus not much smaller than the lower bound on the short-run benefit.

The last column of Table 10 reports the value of these potential long-run effects. Our estimates of short-run congestion relief effects range from $\$ 1.2$ billion to $\$ 4.1$ billion per year. Equivalent long-run effects range from $\$ 1.0$ billion to $\$ 2.6$ billion per year, and even in the "extreme" case of an elasticity of -2 they can reach $\$ 1.9$ billion. These long-run figures include the loss in consumer welfare experienced by individuals who stop traveling, but this welfare loss is second order, ranging from $\$ 13$ million to $\$ 120$ million per year. While the long-run effects are smaller than the short-run effects, they remain economically significant.

One possibility not captured in our calculations above is the potential for households to relocate to a different metropolitan area in response to increased traffic congestion. We are not aware of any studies estimating the effect of within-area travel costs on migration between metropolitan areas. Nevertheless, we can rule out a large impact on the long-run effects due to migration. If we assume that drivers on the heavily affected freeways are the most likely to leave the metropolitan area, then reducing the lower bound on our estimated

\footnotetext{
22 These figures apply to the average freeway. The analogous figures for lightly affected freeways are $87 \%$ and $80 \%$ respectively. The analogous figures for heavily affected freeways are $81 \%$ and $74 \%$ respectively. The difference between short-run and long-run effects is smaller when there is no delay multiplier because the dollar value of the congestion increase becomes smaller as a share of total travel costs.
} 
effect by $20 \%$ requires an elasticity of migration with respect to travel costs of $8.7 .^{23}$ An elasticity of that magnitude is implausibly large - it is equivalent, for example, to assuming that a 10\% increase in Los Angeles-area rents would reduce the Los Angeles population by $80 \% .{ }^{24}$ The large elasticity is necessary in part because delay costs during commute hour represent a minority of annual household travel costs (particularly when applying no delay multiplier, as is the case with the lower-bound estimate). It is also necessary because migration among metropolitan areas does not eliminate congestion but rather reapportions it between areas. In our simulation we assume that households departing Los Angeles move to metropolitan areas with a level of congestion equal to the average across all 439 U.S. metropolitan areas. This implies that for every one hour of congestion eliminated in Los Angeles, approximately 15 minutes of congestion are generated in other urban areas. The congestion relief in Los Angeles is thus partially offset by increased congestion elsewhere. ${ }^{25}$

In summation, it seems likely that the long-run congestion relief benefits of transit service are at least half the size of the short-run benefits. Under any reasonable assumptions, the estimated long-run benefits are still four times larger than estimates in the previous literature. Reducing the long-run effects below $50 \%$ of the lower bound on the short-run effects requires elasticities of implausible magnitude. In fact, the calculations above are conservative in that they ignore long-run behavioral responses that could increase congestion. Chief among these is the likelihood that some former transit riders without cars would purchase cars if the transit system were permanently shut down.

\subsection{Capital Investment}

Previous research has generally concluded that the costs of rail transit capital projects greatly exceed the potential benefits (Baum-Snow and Kahn 2005; Winston and Maheshri

\footnotetext{
${ }^{23}$ Reducing the high end of our estimate effects by $20 \%$ requires an elasticity of migration with respect to travel costs of 2.8. A spreadsheet detailing these calculations is available from the author.

24 The average rent in Los Angeles is approximately $\$ 14,400$ per year ( $\$ 1,200$ per month), and we calculate that the average household spends about $\$ 7,200$ per year in travel costs (travel time and fuel). The elasticity of migration with respect to rents should thus be twice as large as the elasticity of migration with respect to travel costs (17.4 versus 8.7). At an elasticity of 17.4 , a $10 \%$ increase in rents causes $80 \%$ of the population to leave.

25 Offsetting congestion increases will not occur if households move to rural areas, but rural areas are poor substitutes for the Los Angeles area. Furthermore, rural moves may create additional welfare losses by reducing urban agglomeration benefits. For example, if the elasticity of wages with respect to urban density is 0.02 (Combes et al. 2010), the reduction in agglomeration benefits offsets one-quarter of the congestion relief benefit associated with relocating households to rural areas. This figure applies in our lower-bound scenario (i.e., a delay multiplier of 1.0 and no effect of transit service on arterial road congestion). The offsetting share becomes smaller if we apply a higher delay multiplier or assume a larger effect of transit service on arterial road congestion, but the total long-run effect of transit on congestion is of course higher in those scenarios.
} 
2007; Parry and Small 2009). ${ }^{26}$ Are the estimates in this paper large enough to alter that conclusion? To answer this question we consider a back-of-the-envelope calculation comparing costs and benefits.

Table 11 estimates the net benefits of the Los Angeles rail system under several scenarios. The circa-2000 Los Angeles rail system cost $\$ 7.1$ billion to construct (2003 dollars) and transported 85 million passengers in 2010 (48 million during peak hours). We assume that ridership increases linearly (as opposed to exponentially) at historical rates and reaches a maximum capacity of 175 million riders around $2060 .{ }^{27} \mathrm{We}$ value the short-run congestion relief benefit at $\$ 2.50$ per peak-hour transit passenger mile, which comes from assuming a value of time equal to half the median hourly wage, a modest delay multiplier of 1.4 , and a congestion relief benefit on arterial roads that is half the benefit observed on freeways. We assume a high long-run VMT elasticity with respect to total travel costs of -1.5 .

Of course, the average benefit per peak-hour rail passenger mile is less than $\$ 2.50$ because some rail passengers are diverted from bus lines that are shut down when the rail system opens. If we replace the rail service parameters with typical bus service parameters in our choice model, we predict that a bus overlay of the existing rail system would attract $26 \%$ of the current ridership (assuming rail service ceased). We thus assume that $74 \%$ of rail passengers are incremental passengers attracted by the rail system. This assumption generates a capital cost per incremental rider that is somewhat higher than the estimated capital cost per incremental rider for the Washington Metro system (Pickrell 1990). ${ }^{28} \mathrm{We}$ apply a real discount rate of 5\%, which lies at the upper end of discount rates used to evaluate highway infrastructure projects (U.S. Department of Transportation 2003).

The first column of Table 11 presents estimates under these baseline assumptions. The present value of gross benefits is $\$ 13.7$ billion and exceeds the costs by $\$ 6.6$ billion. The subsequent columns test the robustness of this conclusion to variations in key parameters. The second column assumes annual ridership grows half as fast; the gross benefits fall to

\footnotetext{
${ }^{26}$ One exception is Nelson et al. (2007), who estimate that the entire Washington, DC, transit system generates positive net benefits even after accounting for capital costs. However, $76 \%$ of the benefits in their study accrue in the form of consumer surplus among transit riders, which Nelson et al. note must be high by construction since their logit-based model imposes severe welfare costs for completely eliminating traveler options.

${ }^{27}$ Linear growth to 2060 implies an average growth rate of $1.5 \%$ per year and a doubling of core ridership in 40 years. This represents slower ridership growth than that experienced by the San Francisco Bay Area Rapid Transit system (BART) over the past 35 years. BART opened its initial operating segment in 1972 and its core system in 1976. Core system ridership doubled in just 23 years, and from 1977 to 2012 it increased by an average of $2.0 \%$ per year.

28 Pickrell (1990) estimates that the Washington Metro attracted 281,000 new weekday passengers at a capital cost of $\$ 11.5$ billion, or $\$ 40.9$ million per weekday rider. We estimate that Los Angeles attracted 148,000 new weekday passengers at a capital cost of $\$ 7.1$ billion, or $\$ 48.0$ million per weekday rider (all costs converted to 1998 dollars).
} 
$\$ 11.8$ billion but still exceed the costs by $\$ 4.8$ billion. The third column assumes that a bus replacement of the rail system would attract much higher ridership than in the baseline scenario (50\% of rail ridership). Gross benefits are $\$ 12.3$ billion and exceed the costs by $\$ 5.2$ billion, in large part because the cost of operating additional buses to accommodate greater ridership offsets the reduction in benefits from incremental rail passengers. The last column increases the long-run VMT elasticity with respect to total travel costs to the "extreme" case of -2 . Gross benefits are $\$ 12.7$ billion and exceed the costs by $\$ 5.7$ billion. Reducing the gross benefits to less than the costs requires a long-run VMT elasticity with respect to travel costs of -26.2 (equivalent to a VMT elasticity with respect to fuel costs of -5.9 ). ${ }^{29}$ This value lies far outside the range of estimates in the literature and is fundamentally inconsistent with basic time-series evidence on gas prices and VMT. The calculations in Table 11 do not account for the full range of benefits (e.g., reductions in air pollution, consumer surplus, agglomeration externalities, or construction firm profits) or costs (e.g., cost of public funds). Nevertheless, they indicate that capital investments in transit infrastructure may generate substantial positive net benefits - a finding that has previously had little empirical support.

\section{Conclusion}

Using a simple choice model, we show that transit provision should have much larger impacts on traffic congestion than predicted by models that do not incorporate within-city heterogeneity in driving delays. Our regression discontinuity estimates of the effects of a transit strike confirm this prediction, and back-of-the-envelope calculations suggest that the congestion relief externality of a peak-hour transit passenger mile ranges from $\$ 1.20$ to $\$ 4.10$. The lower bounds on potential long-run benefits are at least half those values. Contrary to the conclusions in the existing transportation and urban economics literature, the congestion relief benefits alone may justify transit infrastructure investments.

Both the model calibration and the regression discontinuity estimates apply specifically to the Los Angeles metropolitan area. The exact magnitudes of the effects are thus unlikely to generalize to other U.S. urban areas. Nevertheless, there are good reasons to believe that the qualitative effects of transit on congestion are similar in other large cities. Los Angeles per capita transit ridership and congestion levels are roughly equivalent to those in other large urban areas (244 annual transit passenger miles per capita versus 295, and 0.34 minutes

${ }^{29}$ Consistent with the literature linking gas prices and VMT, we assume in this calculation that the short-run VMT elasticity with respect to gas prices is $20 \%$ of the long-run VMT elasticity, but we cap the maximum value of the short-run elasticity at -1 . 
of delay per VMT versus 0.28$).{ }^{30}$ The effects are less applicable to smaller urban areas (e.g., Buffalo, Fresno, Madison, or Omaha), where congestion levels are three to four times lower than in Los Angeles. At a minimum, however, the results establish the importance of transit in what many consider the prototypical car-centric city.

The results also illustrate a more general point of substantive importance to public policy. In many cases it is logistically or politically infeasible to internalize externalities, and policymakers instead implement second-best policies that lower the cost of activities that mitigate externalities. In these cases, determining who will adopt the mitigating activities is critical in determining a policy's effectiveness. If the mitigating activity is more attractive to individuals who generate greater externalities, then it will be more effective than a calculation using simple population averages would predict. There are numerous potential examples other than mass transit and congestion. For example, programs that encourage home weatherization should be most attractive to households with the highest energy costs. Hybrid and electric vehicle subsidies should be most appealing to drivers who average a high number of VMT per year. Vaccination against hepatitis B should be most attractive to individuals who engage in high-risk sexual activities and needle sharing. Exploring the policy significance of self-selection into mitigating activities in settings such as these may be a useful area of future research.

\section{REFERENCES}

Abrantes, Pedro A.L., and Mark R. Wardman. 2011. "Meta-analysis of UK values of travel time: An update." Transportation Research Part A: Policy and Practice 45(1): 1-17.

American Public Transportation Association. 2011. 2011 Public Transportation Fact Book. Washington, DC.

Auffhammer, M., and R. Kellogg. 2011. "Clearing the Air? The Effects of Gasoline Content Regulation on Air Quality.” American Economic Review 101(6): 2687-2722.

Baum-Snow, Nathaniel, and Matthew E. Kahn. 2005. "Effects of Urban Rail Transit Expansions: Evidence from Sixteen Cities, 1970-2000.” Brookings-Wharton Papers on Urban Affairs 2005(1): 147-206.

Bento, A. M et al. 2012. "Clearing the air? The unintended consequences of the Clean Air Stickers Program in California.” Cornell Applied Economics Dept. Working Paper.

Bento, Antonio M et al. 2009. "Distributional and Efficiency Impacts of Increased US Gasoline Taxes." American Economic Review 99(3): 667-699.

\footnotetext{
${ }^{30}$ Other large urban areas include Atlanta, Boston, Chicago, Dallas-Fort Worth, Detroit, Houston, Miami, Philadelphia, Phoenix, San Diego, San Francisco-Oakland, Seattle, and Washington, DC. We exclude New York-Newark from this category because of its unique attributes, particularly with respect to transit use.
} 
Bernstein, Sharon, David Pierson, and Daniel Hernandez. 2003. "MTA Strike Derails Business." Los Angeles Times: A1.

“Bing Maps.” 2012. http://www.bing.com/maps/.

Cameron, A. Colin, Jonah B. Gelbach, and Douglas L. Miller. 2011. "Robust Inference With Multiway Clustering." Journal of Business \& Economic Statistics 29(2): 238-249.

Chen, Yihsu, and Alexander Whalley. 2012. "Green Infrastructure: The Effects of Urban Rail Transit on Air Quality." American Economic Journal: Economic Policy 3(4): 58-97.

Combes, Pierre-Philippe et al. 2010. "Estimating Agglomeration Economies with History, Geology, and Worker Effects." In Agglomeration Economics, ed. Glaeser, Edward. University of Chicago Press, p. 15-65.

Davis, Lucas W. 2008. “The Effect of Driving Restrictions on Air Quality in Mexico City." Journal of Political Economy 116(1): 38-81.

Dowling, Richard, and Alexander Skabardonis. 2008. "Urban Arterial Speed-Flow Equations for Travel Demand Models." In Innovations in Travel Demand Modeling, Austin, TX: Transportation Research Board of the National Academies, p. 109-113.

Duranton, Gilles, and Matthew A Turner. 2011. "The Fundamental Law of Road Congestion: Evidence from US Cities.” American Economic Review 101(6): 2616-2652.

Evans, Reg. 2009. Demand Elasticities for Car Trips to Central London as revealed by the Central London Congestion Charge. London: Transport for London Policy Analysis Division.

Graham, Daniel J. 2007. "Variable returns to agglomeration and the effect of road traffic congestion." Journal of Urban Economics 62(1): 103-120.

Imbens, Guido W., and Thomas Lemieux. 2008. "Regression discontinuity designs: A guide to practice." Journal of Econometrics 142(2): 615-635.

Knittel, C., and R. Sandler. 2011. "Cleaning the Bathwater with the Baby: The Health CoBenefits of Carbon Pricing in Transportation.” NBER Working Paper 17390.

Litman, Todd. 2004. “Transit Price Elasticities and Cross Elasticities.” Journal of Public Transportation 7(2): 37-58.

Lo, Shih-Che, and Randolph W. Hall. 2006. "Effects of the Los Angeles transit strike on highway congestion." Transportation Research Part A: Policy and Practice 40(10): 903-917.

Nelson, Peter et al. 2007. “Transit in Washington, DC: Current benefits and optimal level of provision." Journal of Urban Economics 62(2): 231-251.

Parry, Ian W.H., and Kenneth A. Small. 2009. "Should Urban Transit Subsidies Be Reduced?" The American Economic Review 99(3): 700-724.

Pickrell, D H. 1990. Urban Rail Transit Projects: Forecast Versus Actual Ridership and Costs. Cambridge, MA: US Department of Transportation.

Prud'homme, Remy, and Chang-Woon Lee. 1999. "Size, Sprawl, Speed and the Efficiency of Cities." Urban Studies 36(11): 1849-1858. 
Rubin, Joel. 2003. "MTA Strike Puts Traffic Officers in Thick of It.” Los Angeles Times: B12.

Rubin, Thomas A., James E. Moore II, and Shin Lee. 1999. "Ten myths about US urban rail systems." Transport Policy 6(1): 57-73.

Schrank, David, and Tim Lomax. 2003. 2003 Annual Urban Mobility Report. College Station, TX: Texas Transportation Institute.

Schrank, David, Tim Lomax, and Bill Eisele. 2011. 2011 Urban Mobility Report. College Station, TX: Texas Transportation Institute.

Small, K A. 2005. "Unnoticed Lessons from London: Road Pricing and Public Transit." Access (26): 10-15.

Small, Kenneth A., and Kurt van Dender. 2007. "Fuel Efficiency and Motor Vehicle Travel: The Declining Rebound Effect." The Energy Journal 28(1): 25-52.

Small, K., and E. Verhoef. 2007. The Economics of Urban Transportation. New York: Routledge.

Stopher, P. 2004. "Reducing road congestion: a reality check." Transport Policy 11(2): 117-131.

Streeter, Kurt, and Karen Bernstein. 2003. “MTA Strike Halts Buses Across L.A.” Los Angeles Times: A1.

Streeter, Kurt, Karen Bernstein, and Caitlin Liu. 2003. "Mediation Plan Ends MTA Strike." Los Angeles Times: A1.

Taylor, B. D. 2004. “The politics of congestion mitigation.” Transport Policy 11(3): 299-302.

Thornberg, C., and J. Haveman. 2010. Los Angeles City Council Districts: 2010 Economic Report. Los Angeles, CA: Beacon Economics.

US Department of Labor. 2006. Employment Cost Index Historical Listing. Washington, DC.

- 2004. Los Angeles-Riverside-Orange County, CA National Compensation Survey April 2004. Washington, DC.

US Department of Transportation. 2003. Economic Analysis Primer. Washington, DC.

—. 2011a. Federal Transit Administration Fiscal Year 2011 Budget Estimates. Washington, DC.

- 2011b. Highway Statistics 2010. Washington, DC.

- 2009. Travel Profile of the United States. Washington, DC. http://nhts.ornl.gov/2009/pub/profile_2012.pdf.

Willson, Richard, and Donald Shoup. 1990. "Parking subsidies and travel choices: Assessing the evidence." Transportation 17(2): 141-157.

Winston, Clifford, and Ashley Langer. 2006. "The effect of government highway spending on road users' congestion costs.” Journal of Urban Economics 60(3): 463-483.

Winston, Clifford, and Vikram Maheshri. 2007. "On the social desirability of urban rail transit systems.” Journal of Urban Economics 62(2): 362-382. 
Figure 1: Los Angeles Freeways and Rail Lines (2003)

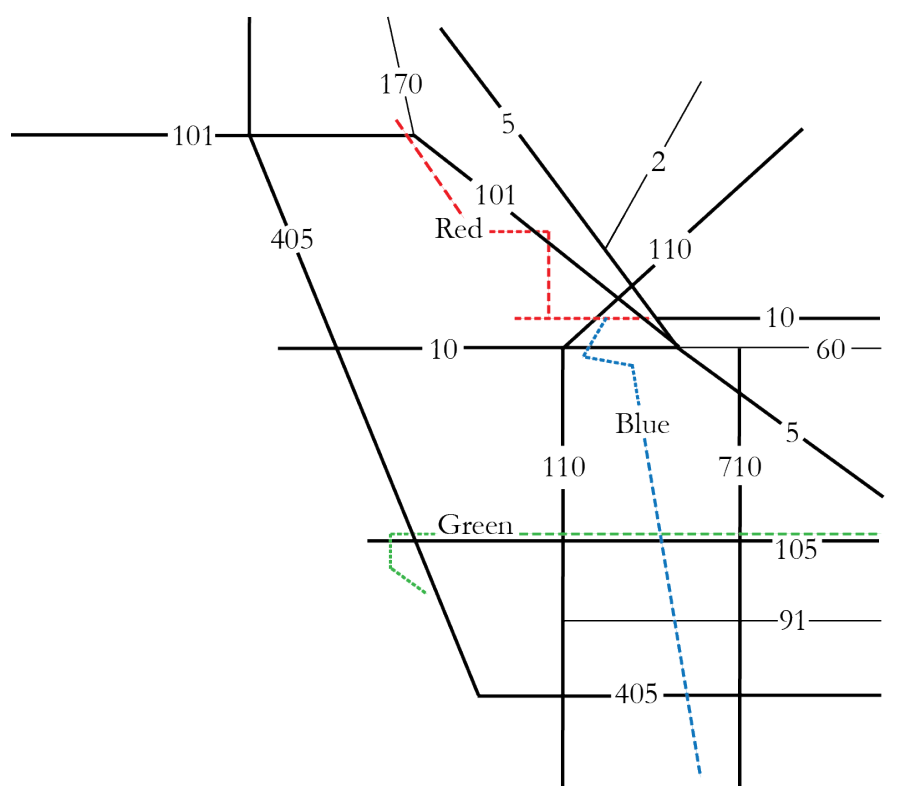

Figure 2: Weekly Peak Hr. Delay on Major L.A. Freeways (7/14/03-1/30/04)

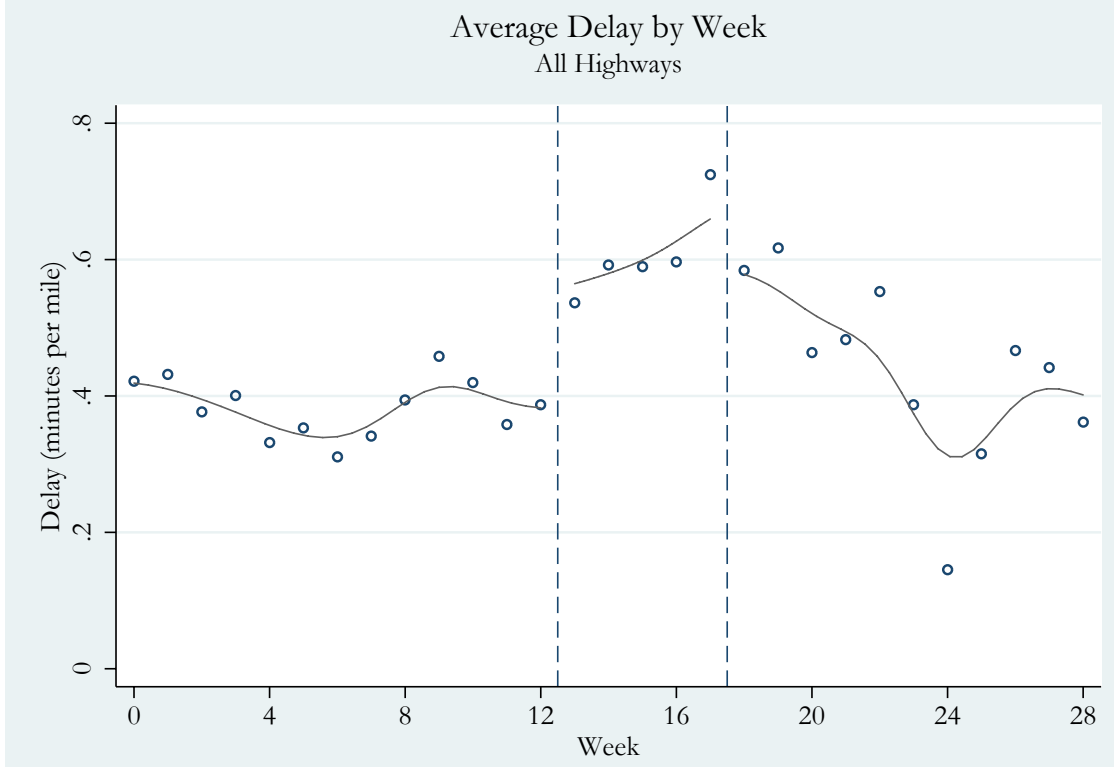


Figure 3: Weekly Peak Hr. Delay on Specific L.A. Freeways (7/14/03-1/30/04)

Panel A: Red Line Freeway (US-101)

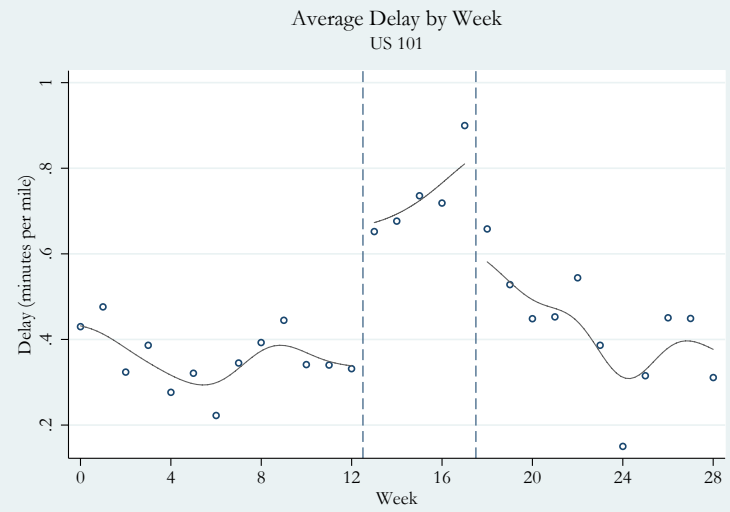

Panel C: Blue Line Freeways (I-110 \& I-710)

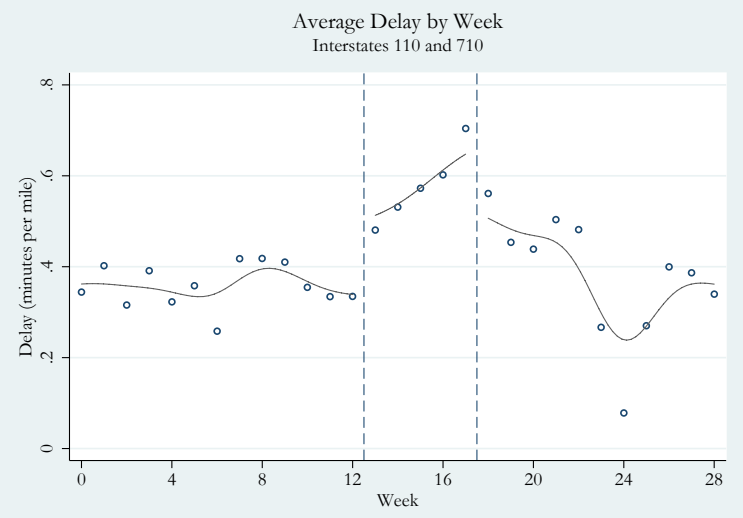

Panel B: Green Line Freeway (I-105)

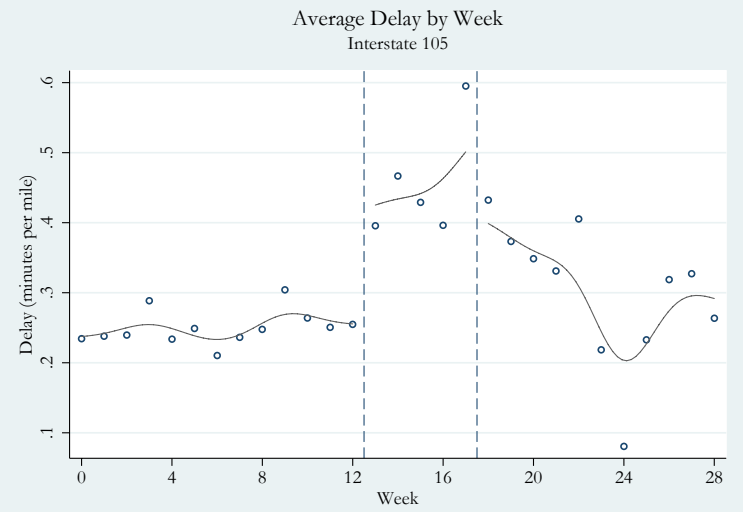

Panel D: Rapid 720 Freeway (I-10)

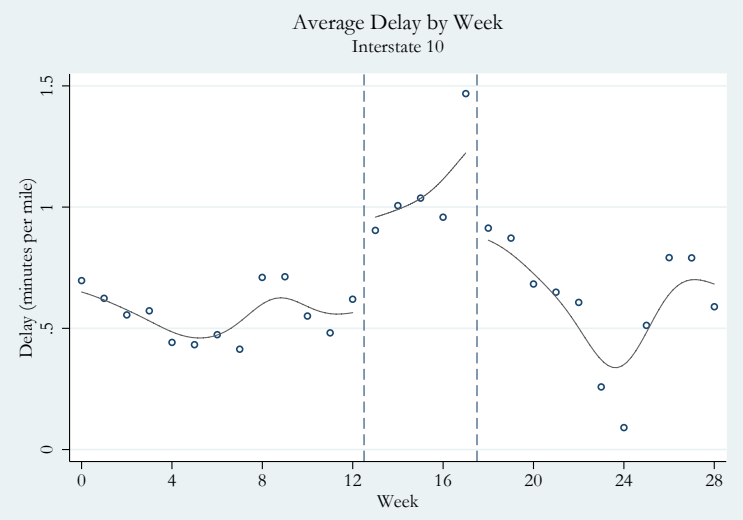

Figure 4: Weekly Peak Hr. Delay on Orange/Ventura County Freeways (7/14/03-1/30/04)

Average Delay by Week

Control Highways

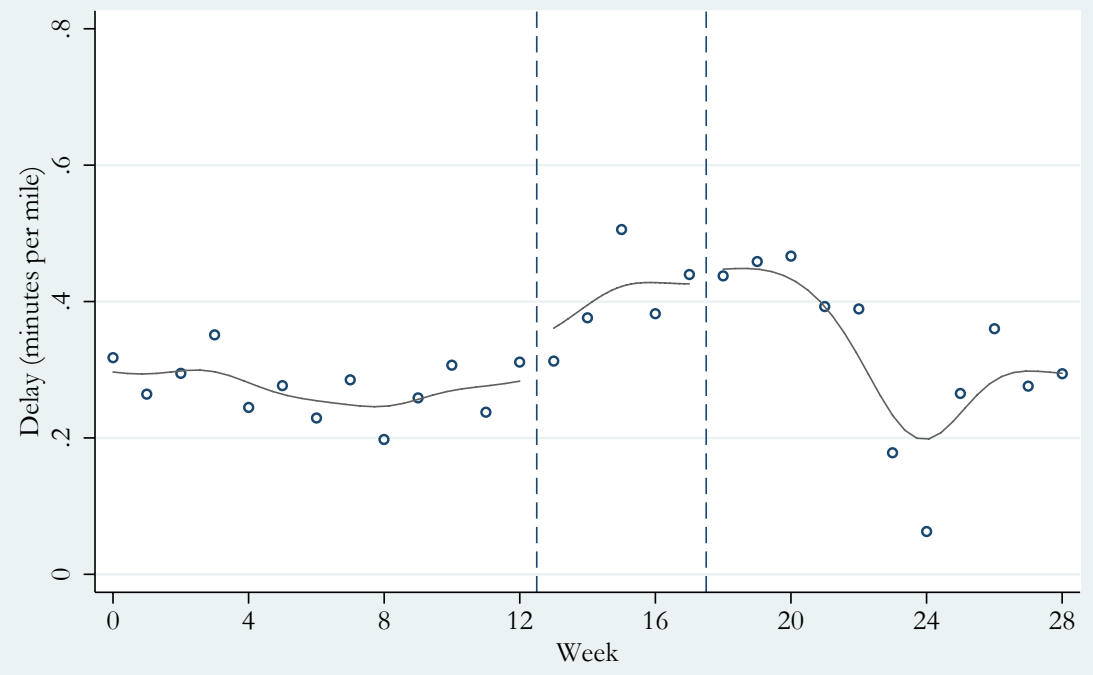


Figure 5: Weekly Peak Hr. Delay on Major L.A. Freeways 1 Year Later (7/14/04-1/30/05)

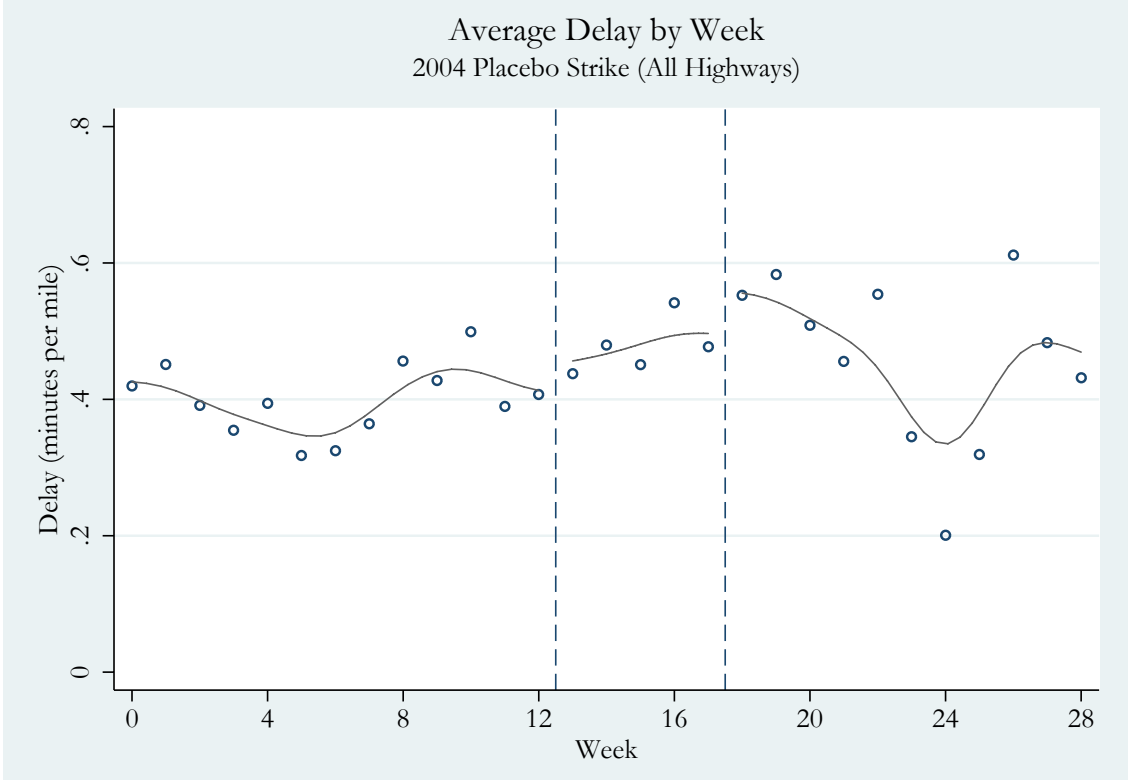

Table 1: Parameter Values for Model Calibration

\begin{tabular}{|c|c|c|c|c|}
\hline Parameter & Related variable & Rail & Bus & Source (where applicable) \\
\hline \multicolumn{5}{|l|}{ General Parameters } \\
\hline Trip Length & $m$ & 7 miles & 5 miles & Parry and Small (2009) \\
\hline Hourly Wage (avg) & $v_{i}$ & \multicolumn{2}{|c|}{$\$ 21.60$} & BLS (2004) \\
\hline Hourly Wage ( $95 \%$ interval) & $v_{i}$ & \multicolumn{2}{|c|}{$\$ 8.00-\$ 65.50$} & BLS (2004) \\
\hline Wage Multiplier for Value of Time & $v_{i}$ & \multicolumn{2}{|c|}{0.5} & Parry and Small (2009) \\
\hline Delay Multiplier & $c$ & \multicolumn{2}{|c|}{1.8} & Parry and Small (2009) \\
\hline \multicolumn{5}{|l|}{ Transit Travel Time and Costs } \\
\hline Transit Vehicle Speed (avg) & $s_{r}, s_{b}$ & $23 \mathrm{mph}$ & $11 \mathrm{mph}$ & Parry and Small (2009) \\
\hline Transit Vehicle Speed (95\% interval) & $s_{r}, s_{b}$ & $23 \mathrm{mph}$ & 8.8-11.6 mph & \\
\hline Avg Time Between Trains/Buses & $w_{r}, w_{b}$ & 7 mins & 8 mins & Los Angeles County MTA \\
\hline Walking Speed & $a_{r}, a_{b}$ & \multicolumn{2}{|c|}{$2.5 \mathrm{mph}$} & \\
\hline Adult Fare (per mile) & $p_{r}, p_{b}$ & $\$ 0.12$ & $\$ 0.17$ & Los Angeles County MTA \\
\hline
\end{tabular}

Driving Travel Time and Costs

Free-flow Driving Speed $\quad s_{d} \quad 40 \mathrm{mph} \quad 35 \mathrm{mph} \quad$ Parry and Small (2009)

Actual Driving Speed (avg) $\quad w_{d} \quad 30 \mathrm{mph} \quad 27.1 \mathrm{mph} \quad$ Parry and Small (2009)

Actual Driving Speed (95\% interval) $\quad w_{d} \quad 14-40 \mathrm{mph} \quad 13.3-35 \mathrm{mph} \quad$ PeMS Data, Bing Maps

$\begin{array}{llcc}\text { Access, Parking, and Egress Time } & a_{d} & 3 \text { mins } & \\ \text { Operating Costs (per mile) } & p_{d} & \$ 0.15 & \text { AAA (2004) }\end{array}$

Share Commuters with Free Parking $\quad p_{d} \quad 85 \%$

Parking Costs (per day) $\quad p_{d} \quad \$ 5.00$

Notes: The delay multiplier applies to time spent waiting for transit, walking, or delayed in traffic. For time spent delayed in traffic, we calculate delay time as the difference between actual driving time and driving time under free-flow conditions. 
Table 2: Model Calibration Results

\begin{tabular}{|c|c|c|}
\hline & $\begin{array}{l}\text { Homogeneous } \\
\text { Driving Speed }\end{array}$ & $\begin{array}{c}\text { Heterogeneous } \\
\text { Driving Speed }\end{array}$ \\
\hline \multicolumn{3}{|l|}{ Outcomes } \\
\hline Avg Delay for Drivers & $0.50 \mathrm{mins} / \mathrm{mile}$ & $0.50 \mathrm{mins} / \mathrm{mile}$ \\
\hline $\begin{array}{l}\text { Avg Delay for Rail Passengers } \\
\text { (if they chose to drive) }\end{array}$ & $0.50 \mathrm{mins} / \mathrm{mile}$ & $3.19 \mathrm{mins} / \mathrm{mile}$ \\
\hline $\begin{array}{l}\text { Avg Delay for Bus Passengers } \\
\text { (if they chose to drive) }\end{array}$ & $0.50 \mathrm{mins} / \mathrm{mile}$ & $2.47 \mathrm{mins} / \mathrm{mile}$ \\
\hline Effect of Ceasing Transit on Average Delay & $0.032 \mathrm{mins} / \mathrm{mile}$ & $0.189 \mathrm{mins} / \mathrm{mile}$ \\
\hline Avg Consumer Surplus for Rail Passengers & $\$ 0.08 /$ mile & $\$ 0.24 /$ mile \\
\hline Avg Consumer Surplus for Bus Passengers & $\$ 0.04 /$ mile & $\$ 0.11 /$ mile \\
\hline \multicolumn{3}{|l|}{ Calibration Parameters } \\
\hline Share of Population within 2 miles of Rail Line & $51 \%$ & $30 \%$ \\
\hline Average Bus Line Spacing in Residential Areas & 0.4 miles & 0.5 miles \\
\hline
\end{tabular}

Table 3: Summary Statistics

\begin{tabular}{|c|c|c|c|c|}
\hline & \multicolumn{2}{|c|}{ Unweighted Statistics } & \multicolumn{2}{|c|}{ VMT-Weighted Statistics } \\
\hline & No Strike & During Strike & No Strike & During Strike \\
\hline Lanes & $\begin{array}{c}3.3 \\
(1.4)\end{array}$ & $\begin{array}{c}3.3 \\
(1.4)\end{array}$ & $\begin{array}{c}3.2 \\
(1.5)\end{array}$ & $\begin{array}{c}3.2 \\
(1.5)\end{array}$ \\
\hline $\begin{array}{l}\text { Total Flow } \\
\text { (vehicles per hour) }\end{array}$ & $\begin{array}{l}4,619 \\
(2,602)\end{array}$ & $\begin{array}{c}4,604 \\
(2,531)\end{array}$ & $\begin{array}{l}4,401 \\
(2,730)\end{array}$ & $\begin{array}{l}4,355 \\
(2,674)\end{array}$ \\
\hline Average Speed (mph) & $\begin{array}{c}53.3 \\
(15.9)\end{array}$ & $\begin{array}{c}49.3 \\
(17.4)\end{array}$ & $\begin{array}{c}52.8 \\
(16.6)\end{array}$ & $\begin{array}{c}48.3 \\
(17.9)\end{array}$ \\
\hline $\begin{array}{l}\text { Delay Relative to } 55 \mathrm{mph} \\
\text { (minutes per mile) }\end{array}$ & $\begin{array}{l}0.35 \\
(0.83)\end{array}$ & $\begin{array}{c}0.52 \\
(1.05)\end{array}$ & $\begin{array}{c}0.37 \\
(0.81)\end{array}$ & $\begin{array}{c}0.55 \\
(1.01)\end{array}$ \\
\hline $\begin{array}{l}\text { Delay Relative to } 60 \mathrm{mph} \\
\text { (minutes per mile) }\end{array}$ & $\begin{array}{c}0.39 \\
(0.85)\end{array}$ & $\begin{array}{c}0.57 \\
(1.07)\end{array}$ & $\begin{array}{c}0.41 \\
(0.83)\end{array}$ & $\begin{array}{c}0.61 \\
(1.04)\end{array}$ \\
\hline $\begin{array}{l}\text { Delay Relative to } 65 \mathrm{mph} \\
\text { (minutes per mile) }\end{array}$ & $\begin{array}{c}0.43 \\
(0.87)\end{array}$ & $\begin{array}{c}0.62 \\
(1.09)\end{array}$ & $\begin{array}{c}0.45 \\
(0.85)\end{array}$ & $\begin{array}{c}0.66 \\
(1.05)\end{array}$ \\
\hline $\begin{array}{l}\text { Average Share of Time } \\
\text { Occupied }\end{array}$ & $\begin{array}{c}0.101 \\
(0.072)\end{array}$ & $\begin{array}{c}0.115 \\
(0.082)\end{array}$ & $\begin{array}{c}0.110 \\
(0.071)\end{array}$ & $\begin{array}{c}0.125 \\
(0.080)\end{array}$ \\
\hline Detectors in Service & 720 & 640 & 720 & 640 \\
\hline Sample Size & 509,946 & 110,844 & 509,946 & 110,844 \\
\hline
\end{tabular}


Table 4: Effect of Strike on Delays During All Peak Hours

\begin{tabular}{|c|c|c|c|c|c|c|}
\hline & $(1)$ & $(2)$ & (3) & (4) & (5) & (6) \\
\hline Strike & $\begin{array}{c}0.194 \\
(0.041)\end{array}$ & $\begin{array}{c}0.332 \\
(0.076)\end{array}$ & $\begin{array}{c}0.218 \\
(0.052)\end{array}$ & $\begin{array}{c}0.190 \\
(0.051)\end{array}$ & $\begin{array}{c}0.357 \\
(0.128)\end{array}$ & $\begin{array}{c}0.125 \\
(0.042)\end{array}$ \\
\hline Date & $\begin{array}{l}-0.004 \\
(0.002)\end{array}$ & $\begin{array}{l}-0.003 \\
(0.003)\end{array}$ & $\begin{array}{l}-0.002 \\
(0.002)\end{array}$ & $\begin{array}{l}-0.003 \\
(0.002)\end{array}$ & $\begin{array}{l}-0.005 \\
(0.004)\end{array}$ & $\begin{array}{l}-0.005 \\
(0.002)\end{array}$ \\
\hline Date*Strike & $\begin{array}{c}0.007 \\
(0.002)\end{array}$ & $\begin{array}{c}0.006 \\
(0.003)\end{array}$ & $\begin{array}{l}-0.001 \\
(0.002)\end{array}$ & $\begin{array}{c}0.007 \\
(0.003)\end{array}$ & $\begin{array}{c}0.012 \\
(0.007)\end{array}$ & $\begin{array}{c}0.007 \\
(0.002)\end{array}$ \\
\hline Average Delay Pre-Strike & 0.409 & 0.369 & 0.264 & 0.357 & 0.600 & 0.434 \\
\hline Freeways & All & 101 & 105 & $110 \& 710$ & 10 & Other \\
\hline Parallel Transit Line & & Red Line & Green Line & Blue Line & Rapid 720 & \\
\hline Sample Size & 178,549 & 15,854 & 31,058 & 19,152 & 15,357 & 97,128 \\
\hline
\end{tabular}


Table 5: Effect of Strike on Delays During AM Peak Hours

\begin{tabular}{|c|c|c|c|c|c|c|}
\hline & $(1)$ & (2) & (3) & (4) & (5) & $(6)$ \\
\hline Strike & $\begin{array}{c}0.314 \\
(0.075)\end{array}$ & $\begin{array}{c}0.482 \\
(0.148)\end{array}$ & $\begin{array}{c}0.283 \\
(0.090)\end{array}$ & $\begin{array}{c}0.189 \\
(0.073)\end{array}$ & $\begin{array}{c}0.619 \\
(0.179)\end{array}$ & $\begin{array}{c}0.258 \\
(0.079)\end{array}$ \\
\hline Date & $\begin{array}{l}-0.003 \\
(0.003)\end{array}$ & $\begin{array}{l}-0.003 \\
(0.005)\end{array}$ & $\begin{array}{c}0.003 \\
(0.002)\end{array}$ & $\begin{array}{l}-0.002 \\
(0.004)\end{array}$ & $\begin{array}{l}-0.013 \\
(0.009)\end{array}$ & $\begin{array}{l}-0.003 \\
(0.004)\end{array}$ \\
\hline Date*Strike & $\begin{array}{c}0.000 \\
(0.005)\end{array}$ & $\begin{array}{l}-0.005 \\
(0.007)\end{array}$ & $\begin{array}{l}-0.012 \\
(0.004)\end{array}$ & $\begin{array}{c}0.008 \\
(0.006)\end{array}$ & $\begin{array}{c}0.010 \\
(0.012)\end{array}$ & $\begin{array}{c}0.001 \\
(0.005)\end{array}$ \\
\hline Average Delay Pre-Strike & 0.472 & 0.392 & 0.268 & 0.485 & 0.953 & 0.464 \\
\hline Freeways & All & 101 & 105 & $110 \& 710$ & 10 & Other \\
\hline Parallel Transit Line & & Red Line & Green Line & Blue Line & Rapid 720 & \\
\hline Sample Size & 58,380 & 5,210 & 10,136 & 6,214 & 5,074 & 31,746 \\
\hline
\end{tabular}


Table 6: Effect of Strike on Delays During PM Peak Hours

\begin{tabular}{|c|c|c|c|c|c|c|}
\hline \multicolumn{7}{|c|}{ Dependent Variable: Average Delay (in minutes per mile) } \\
\hline Strike & $\begin{array}{c}0.157 \\
(0.040)\end{array}$ & $\begin{array}{c}0.266 \\
(0.064)\end{array}$ & $\begin{array}{c}0.213 \\
(0.061)\end{array}$ & $\begin{array}{c}0.197 \\
(0.056)\end{array}$ & $\begin{array}{c}0.279 \\
(0.132)\end{array}$ & $\begin{array}{c}0.085 \\
(0.049)\end{array}$ \\
\hline Date & $\begin{array}{l}-0.005 \\
(0.002)\end{array}$ & $\begin{array}{c}-0.004 \\
(0.003)\end{array}$ & $\begin{array}{l}-0.005 \\
(0.002)\end{array}$ & $\begin{array}{c}-0.004 \\
(0.002)\end{array}$ & $\begin{array}{c}-0.004 \\
(0.005)\end{array}$ & $\begin{array}{l}-0.006 \\
(0.002)\end{array}$ \\
\hline Date*Strike & $\begin{array}{c}0.010 \\
(0.002)\end{array}$ & $\begin{array}{c}0.011 \\
(0.004)\end{array}$ & $\begin{array}{c}0.005 \\
(0.002)\end{array}$ & $\begin{array}{c}0.007 \\
(0.002)\end{array}$ & $\begin{array}{c}0.017 \\
(0.008)\end{array}$ & $\begin{array}{c}0.011 \\
(0.002)\end{array}$ \\
\hline Average Delay Pre-Strike & 0.384 & 0.361 & 0.274 & 0.300 & 0.401 & 0.431 \\
\hline Freeways & All & 101 & 105 & $110 \& 710$ & 10 & Other \\
\hline Parallel Transit Line & & Red Line & Green Line & Blue Line & Rapid 720 & \\
\hline Sample Size & 120,007 & 10,575 & 20,922 & 12,938 & 10,283 & 65,289 \\
\hline $\begin{array}{l}\text { Notes: Each column repr } \\
\text { covered by detector i)*(av } \\
\text { sample is limited to week } \\
\text { standard errors that are r } \\
\text { week and detector fixed ef }\end{array}$ & $\begin{array}{l}\text { separate } \\
\text {-strike tra } \\
2-8 \mathrm{pm} \\
\text { within-day }\end{array}$ & $\begin{array}{l}\text {-weightec } \\
\text { ow over c } \\
\text { n } 28 \text { days } \\
\text { within-d }\end{array}$ & $\begin{array}{l}\text { gression, w } \\
\text { ctor i). The } \\
\text { the strike's } \\
\text { tor serial co }\end{array}$ & $\begin{array}{l}\text { weights } \\
\text { bservation } \\
\text { eginning. } \\
\text { elation. A }\end{array}$ & $\begin{array}{l}\text { al to (lengt } \\
\text { he detector } \\
\text { ntheses co } \\
\text { gressions }\end{array}$ & $\begin{array}{l}\text { of highw } \\
\text { ur, and } t \\
\text { n cluster } \\
\text { ade day-c }\end{array}$ \\
\hline
\end{tabular}


Table 7: Effect of Strike on Freeway Occupancy

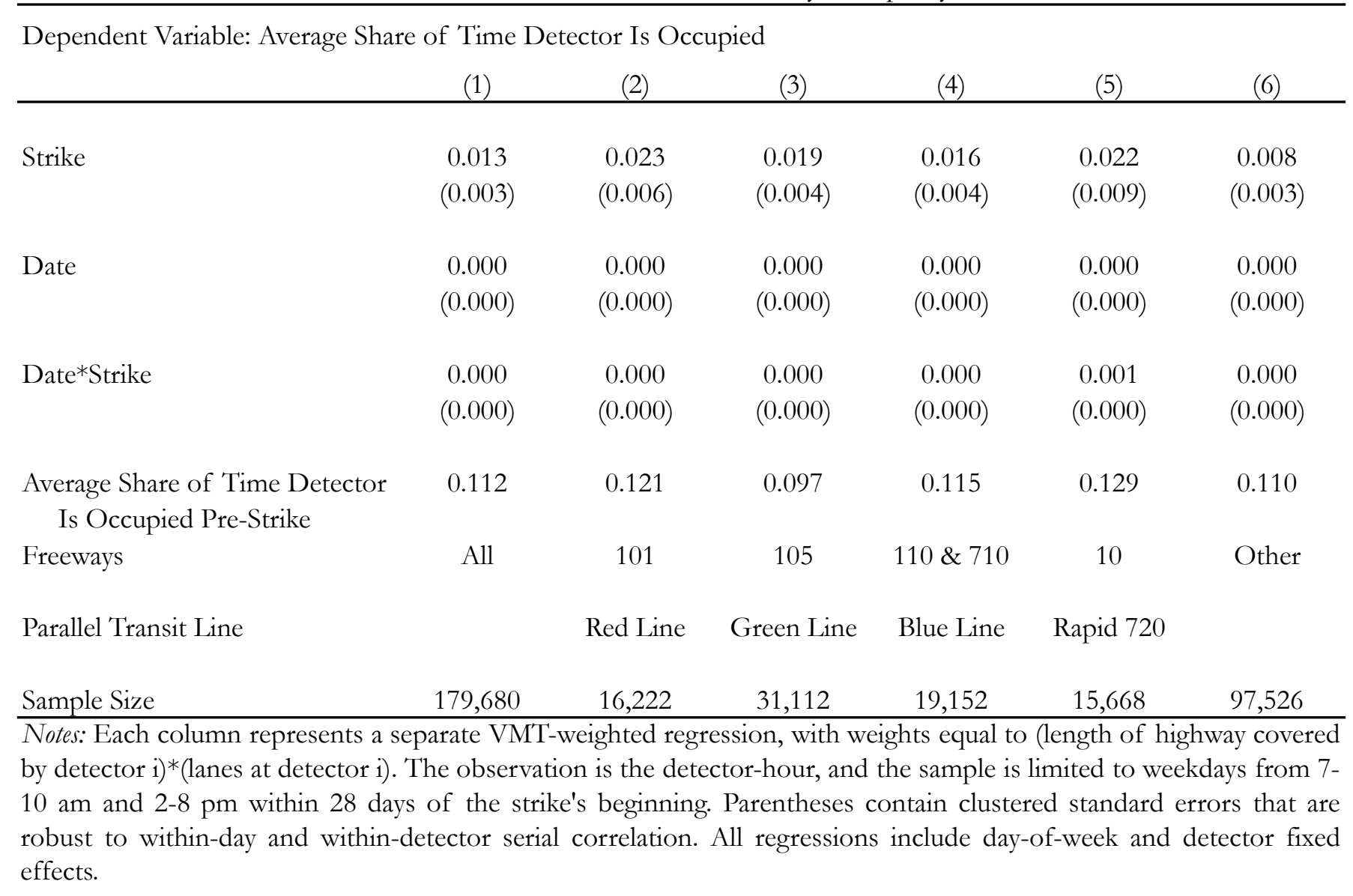


Table 8: Effect of Strike on Traffic Flows

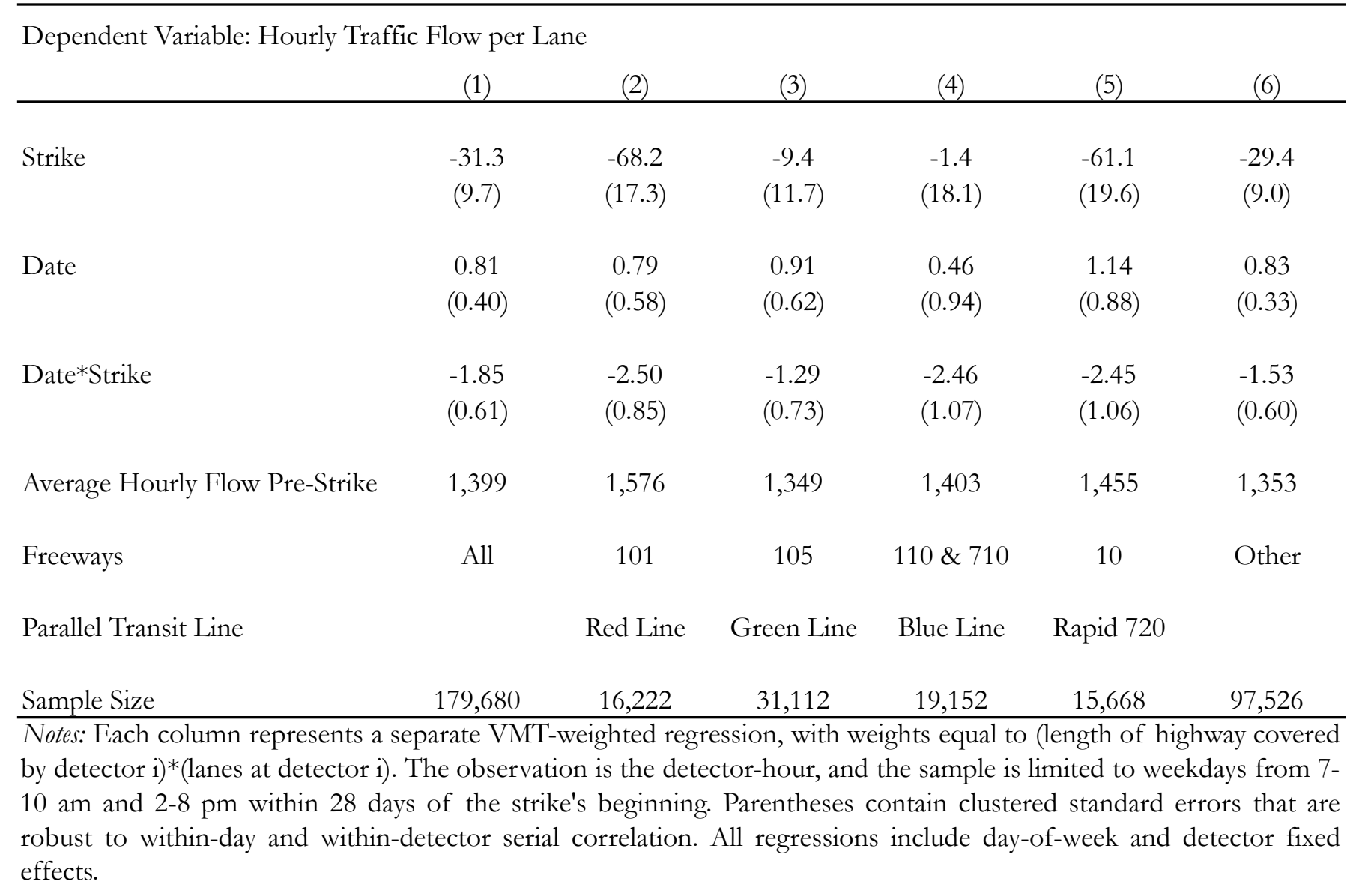


Table 9: Effect of Placebo Strikes on Delays

\begin{tabular}{|c|c|c|c|c|c|c|}
\hline \multicolumn{7}{|c|}{ Dependent Variable: Average Delay (in minutes per mile) } \\
\hline \multirow[t]{2}{*}{ Falsification Sample: } & \multicolumn{3}{|c|}{ Orange and Ventura Counties } & \multicolumn{3}{|c|}{ October/November 2004} \\
\hline & $(1)$ & $(2)$ & (3) & $(4)$ & $(5)$ & $(6)$ \\
\hline Strike & $\begin{array}{c}0.024 \\
(0.027)\end{array}$ & $\begin{array}{c}0.025 \\
(0.037)\end{array}$ & $\begin{array}{c}0.026 \\
(0.037)\end{array}$ & $\begin{array}{c}0.060 \\
(0.042)\end{array}$ & $\begin{array}{c}0.082 \\
(0.054)\end{array}$ & $\begin{array}{c}0.045 \\
(0.064)\end{array}$ \\
\hline Date & $\begin{array}{c}0.000 \\
(0.001)\end{array}$ & $\begin{array}{l}-0.001 \\
(0.003)\end{array}$ & $\begin{array}{c}0.000 \\
(0.002)\end{array}$ & $\begin{array}{l}-0.002 \\
(0.002)\end{array}$ & $\begin{array}{l}-0.002 \\
(0.003)\end{array}$ & $\begin{array}{l}-0.003 \\
(0.002)\end{array}$ \\
\hline Date*Strike & $\begin{array}{c}0.004 \\
(0.002)\end{array}$ & $\begin{array}{c}0.000 \\
(0.003)\end{array}$ & $\begin{array}{c}0.006 \\
(0.003)\end{array}$ & $\begin{array}{c}0.005 \\
(0.003)\end{array}$ & $\begin{array}{c}0.002 \\
(0.003)\end{array}$ & $\begin{array}{c}0.007 \\
(0.004)\end{array}$ \\
\hline Average Delay Pre-Strike & 0.205 & 0.170 & 0.219 & 0.433 & 0.539 & 0.386 \\
\hline Hours & All Peak & AM Peak & PM Peak & All Peak & AM Peak & PM Peak \\
\hline Sample Size & 13,149 & 4,296 & 8,853 & 177,572 & 59,532 & 118,034 \\
\hline \multicolumn{7}{|c|}{$\begin{array}{l}\text { Notes: Each column represents a separate VMT-weighted regression, with weights equal to (length of highway covered by } \\
\text { detector i)*(average pre-strike traffic flow over detector i). The observation is the detector-hour, and the sample is limited } \\
\text { to weekdays from } 7-10 \mathrm{am} \text { and } 2-8 \mathrm{pm} \text { within } 28 \text { days of the strike's beginning. Parentheses contain clustered standard } \\
\text { errors that are robust to within-day and within-detector serial correlation. All regressions include day-of-week and detector } \\
\text { fixed effects. In Columns (1)-(3) the strike variable is defined normally but the sample contains detectors in neighboring } \\
\text { counties not subject to the strike. In columns (4)-(6) the strike variable equals zero prior to October 12, } 2004 \text { and unity } \\
\text { after October 12, 2004. }\end{array}$} \\
\hline
\end{tabular}


Table 10: Potential Long-run Effects

\begin{tabular}{|c|c|c|c|c|c|c|c|c|}
\hline \multirow[b]{2}{*}{ Travel Response Parameter } & \multirow[b]{2}{*}{$\begin{array}{c}\text { Implied generalized } \\
\text { travel cost elasticity } \\
\text { of VMT }\end{array}$} & \multicolumn{3}{|c|}{ Long-run equilibrium travel demand reduction } & \multicolumn{3}{|c|}{ Long-run effect as a $\%$ of short-run effect } & \multirow{2}{*}{$\begin{array}{l}\text { Long-run } \\
\text { annual } \\
\text { congestion } \\
\text { relief benefit }\end{array}$} \\
\hline & & $\begin{array}{l}\text { Lightly- } \\
\text { affected } \\
\text { freeways }\end{array}$ & $\begin{array}{l}\text { Average } \\
\text { freeway }\end{array}$ & $\begin{array}{l}\text { Heavily- } \\
\text { affected } \\
\text { freeways }\end{array}$ & $\begin{array}{l}\text { Lightly- } \\
\text { affected } \\
\text { freeways }\end{array}$ & $\begin{array}{l}\text { Average } \\
\text { freeway }\end{array}$ & $\begin{array}{l}\text { Heavily- } \\
\text { affected } \\
\text { freeways }\end{array}$ & \\
\hline \multicolumn{9}{|c|}{ Panel A: Delay Multiplier $=1.8$, Arterial Congestion } \\
\hline Fuel price elasticity of VMT $=-0.15$ & -0.67 & $-2.5 \%$ & $-3.9 \%$ & $-6.7 \%$ & $63 \%$ & $62 \%$ & $56 \%$ & $\$ 2.6$ billion \\
\hline Fuel price elasticity of VMT $=-0.34$ & -1.5 & $-3.3 \%$ & $-5.2 \%$ & $-8.9 \%$ & $51 \%$ & $49 \%$ & $45 \%$ & $\$ 2.1$ billion \\
\hline London Congestion Charge Response & -2.0 & $-3.6 \%$ & $-5.7 \%$ & $-9.7 \%$ & $46 \%$ & $45 \%$ & $40 \%$ & $\$ 1.9$ billion \\
\hline \multicolumn{9}{|c|}{ Panel B: No Delay Multiplier, No Arterial Congestion } \\
\hline Fuel price elasticity of VMT $=-0.15$ & -0.67 & $-0.8 \%$ & $-1.5 \%$ & $-2.5 \%$ & $87 \%$ & $85 \%$ & $81 \%$ & $\$ 1$ billion \\
\hline Fuel price elasticity of VMT $=-0.34$ & -1.5 & $-1.3 \%$ & $-2.1 \%$ & $-3.7 \%$ & $80 \%$ & $79 \%$ & $74 \%$ & $\$ 1$ billion \\
\hline London Congestion Charge Response & -2.0 & $-1.5 \%$ & $-2.5 \%$ & $-4.3 \%$ & $77 \%$ & $75 \%$ & $70 \%$ & $\$ 1$ billion \\
\hline
\end{tabular}

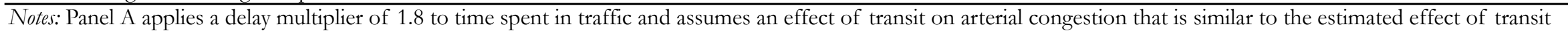
on freeway congestion. Panel B applies no delay multiplier and assumes transit has no effect on arterial congestion. 
Table 11: Capital Investment Benefits

\begin{tabular}{|c|c|c|c|c|}
\hline & Baseline & $\begin{array}{l}\text { Low Ridership } \\
\text { Growth }\end{array}$ & $\begin{array}{l}\text { High Bus } \\
\text { Ridership }\end{array}$ & $\begin{array}{c}\text { "Extreme" } \\
\text { VMT Elasticity }\end{array}$ \\
\hline \multicolumn{5}{|l|}{ Fixed Parameters } \\
\hline 2001 Ridership (Red, Green, Blue Lines) & 69 million & - & - & - \\
\hline 2010 Ridership (Red, Green, Blue Lines) & 85 million & - & - & - \\
\hline Share of Ridership that is Peak Hour & $57 \%$ & - & - & - \\
\hline 2010 Rail Operating Subsidy (\$2003) & $\$ 115$ million & - & - & - \\
\hline Annual Real Wage Growth & $1 \%$ & - & - & - \\
\hline Real Discount Rate & $5 \%$ & - & - & - \\
\hline $\begin{array}{l}\text { Short-run Congestion Relief Benefit per Peak Mile } \\
\text { Varying Parameters }\end{array}$ & $\$ 2.50$ & - & - & - \\
\hline Annual Ridership Growth (to max of 175 million) & 1.7 million & 0.9 million & - & - \\
\hline Share Riders Retained if Replacing Rail with Bus & $26 \%$ & - & $50 \%$ & - \\
\hline 2010 Operating Subsidy if Replacing Rail with Bus & $\$ 126$ million & - & $\$ 215$ million & - \\
\hline VMT Elasticity wrt Total Travel Costs & -1.5 & - & - & -2.0 \\
\hline Long-run Congestion Relief Benefit per Peak Mile & $\$ 1.61$ & - & - & $\$ 1.50$ \\
\hline \multicolumn{5}{|l|}{ Total Costs and Benefits } \\
\hline Capital Cost of Rail System & $\$ 7.1$ billion & $\$ 7.1$ billion & $\$ 7.1$ billion & $\$ 7.1$ billion \\
\hline Present Value of Gross Benefits & $\$ 13.7$ billion & $\$ 11.8$ billion & $\$ 12.3$ billion & $\$ 12.7$ billion \\
\hline Present Value of Net Benefits & $\$ 6.6$ billion & $\$ 4.8$ billion & $\$ 5.2$ billion & $\$ 5.7$ billion \\
\hline
\end{tabular}




\section{ONLINE APPENDIX (NOT FOR PRINT PUBLICATION)}

\section{A1. Mathematical Appendix}

Suppose that bus lines are placed in a grid pattern of width $2 a$, that the population is uniformly distributed across space, and that people cannot walk diagonally across city blocks. Further suppose that bus stops are placed at locations at which bus lines cross (this assumption simplifies notation but can be relaxed with minimal effect on our conclusions). Then accessing the nearest bus stop requires walking $U$ miles north/south and $V$ miles east/west, where $U$ and $V$ are independent and each is distributed uniform $(0, a)$. The random variable $X=U+V$ measures the distance to the nearest bus stop and follows a triangular distribution with density $f(x)=x / a^{2}$ for $x \in(0, a)$ and density $f(x)=2 / a-x / a^{2}$ for $x \in(a, 2 a)$.

Proof:

$$
\begin{aligned}
& \text { First note that } f(u, v)=f(u) \cdot f(v)=\frac{1}{a^{2}} . \\
& \text { Thus for } x \in(0, a), P(X<x)=P(U+V<x) \\
& =\int_{0}^{x} \int_{0}^{x-u} \frac{1}{a^{2}} d v d u=\frac{x^{2}}{2 a^{2}} . \\
& \text { Therefore } f(x)=x / a^{2} \text { for } x \in(0, a) . \\
& \text { By symmetry } f(x)=2 / a-x / a^{2} \text { for } x \in(a, 2 a) .
\end{aligned}
$$

\section{A2. Sensitivity of Model Calibration Results}

In this section we test the sensitivity of our calibration results to alternative parameter choices. In our baseline calibration we choose parameter values that tend to lower the cost of transit and increase the cost of driving. These choices are conservative in that they lower the predicted effect of ceasing transit service under the heterogeneous driving delay model. However, in several cases the parameter choices do not have clear implications for the relative cost of driving versus transit. These cases include the delay multiplier (which applies to driving delays, transit wait, and transit access time), the wage multiplier, and trip length.

Table A1 tests the sensitivity of our predictions to reasonable variations in these three parameters. Column (1) reproduces the predictions from our baseline calibration for 
comparison purposes. In the baseline calibration, the heterogeneous driving delay model predicts a congestion impact from ceasing transit service that is 5.9 times greater than the homogeneous driving delay model's prediction. Columns (2) and (3) test sensitivity to variations in the delay multiplier, which is set at $c=1.8$ in our baseline calibration (a delay multiplier of 1.8 implies that individuals value time spent waiting in traffic, waiting for transit, or walking to transit at 1.8 times their normal value of time). Under a high delay multiplier ( $c$ $=2.3$ ), the ratio of the heterogeneous model prediction to the homogeneous model prediction increases to 7.7. Under a low delay multiplier $(c=1.3)$, the ratio decreases to 3.4. Columns (4) and (5) test sensitivity to variations in the value of time. Under a high value of time ( $60 \%$ of the average wage), the ratio of the two models' predictions increases to 7.6. Under a low value of time ( $40 \%$ of the average wage), the ratio decreases to 4.1. Columns (6) and (7) test sensitivity to variations in trip length. Since long and short trips are less common than average-length trips, we calibrate the model in these two columns so that predicted transit share is half the overall transit share. This reduces the predicted impact of ceasing transit service under either model (homogeneous or heterogeneous), but it has little impact on the ratio of the two predictions (which is the object of interest). On long trips (a 10-mile rail trip or a 7-mile bus trip), the ratio of the two predictions is 6.1. On short trips (a 5-mile rail trip or a 3 -mile bus trip), the ratio of the two predictions is 3.6.

Table A2 tests the sensitivity of our predictions to different assumptions about transportation alternatives and sorting behavior. Column (1) reproduces the predictions from our baseline calibration for comparison purposes. Column (2) calibrates the two models under the assumption that one-third of the bus riders are "captive" riders who do not own cars. Under this assumption the predicted impact of ceasing transit service falls in both models because captive riders do not switch to driving. Nevertheless, the ratio of the two models' predictions is nearly unchanged at 6.1. Column (3) calibrates the two models under the assumption that access time and driving delays are negatively correlated (i.e., people living far from transit experience fewer driving delays). This modification captures the possibility that denser areas have better transit access and more congestion. The ratio of the two predictions increases to 6.5. Column (4) calibrates the two models under the assumption that access time and value of time are positively correlated (i.e., wealthy neighborhoods are farther from transit). This modification captures the possibility that lowincome individuals choose to live closer to transit. The ratio of the two predictions decreases to 4.6. 
Two patterns emerge from the sensitivity analyses in Tables A1 and A2. First, in all cases the heterogeneous driving delay model predicts a much greater increase in congestion from ceasing transit service than the homogeneous driving delay model. The minimum ratio between the two models' predictions is 3.4, and the maximum ratio is 7.7. Second, despite the consistent qualitative finding that a model incorporating heterogeneous driving delays predicts much greater congestion impacts, the magnitude of the predictions varies substantially with different parameter values. Thus it is infeasible to make an accurate quantitative prediction about the effect of ceasing transit service without additional data or a natural experiment. 
Table A1: Model Calibration Results Under Different Parameter Values

\begin{tabular}{|c|c|c|c|c|c|c|c|}
\hline & $(1)$ & (2) & (3) & (4) & (5) & $(6)$ & (7) \\
\hline Parameter Modification: & None & $\begin{array}{l}\text { High Delay } \\
\text { Multiplier } \\
(\mathrm{c}=2.3)\end{array}$ & $\begin{array}{l}\text { Low Delay } \\
\text { Multiplier } \\
(\mathrm{c}=1.3)\end{array}$ & $\begin{array}{c}\text { High Value } \\
\text { of Time } \\
(60 \% \text { avg wage })\end{array}$ & $\begin{array}{c}\text { Low Value } \\
\text { of Time } \\
\text { (40\% avg wage) }\end{array}$ & $\begin{array}{c}\text { Long Trip } \\
\text { (Rail }=10 \text { miles, } \\
\text { Bus }=7 \text { miles) }\end{array}$ & $\begin{array}{c}\text { Short Trip } \\
\text { (Rail }=5 \text { miles, } \\
\text { Bus }=3 \text { miles })\end{array}$ \\
\hline
\end{tabular}

\section{Outcomes}

Effect of Ceasing Transit on Average Delay

$\begin{array}{lcc}6.3 \% & 6.4 \% & 6.4 \% \\ 37.1 \% & 49.3 \% & 21.5 \\ 5.9 & 7.7 & 3.4\end{array}$

$6.4 \%$

$6.3 \%$

$6.3 \%$

$3.1 \%$

$3.1 \%$

Effect of Ceasing Transit on Average Delay

(Heterogeneous Driving Delay Model)

Ratio of Heterogeneous Model Effect

to Homogeneous Model Effect

Calibration Parameters (Heterogeneous Model)

Share of Population within 2 miles of Rail Line

Average Bus Line Spacing in Residential Areas

0.5 miles

0.5 miles

0.5 miles

0.3 miles

0.7 miles

0.6 miles

0.6 miles

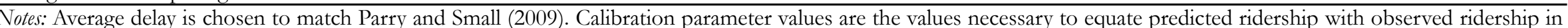

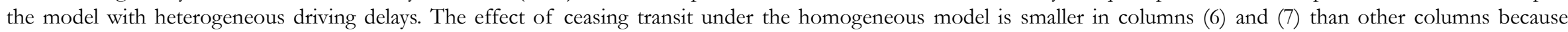
observed ridership for long/short trips is assumed to be half the observed ridership for the average trip. 
Table A2: Model Calibration Results Under Different Parameter Values

\begin{tabular}{|c|c|c|c|c|c|}
\hline & $(1)$ & $(2)$ & (3) & $(4)$ & $(5)$ \\
\hline Parameter Modification: & None & $\begin{array}{l}1 / 3 \text { of Bus Riders } \\
\text { are "Captive" }\end{array}$ & $\begin{array}{c}\text { Access Time and Delays } \\
\text { Negatively Correlated }\end{array}$ & $\begin{array}{c}\text { Access Time and Value } \\
\text { of Time Positively } \\
\text { Correlated }\end{array}$ & $\begin{array}{c}\text { Bus Access Time } \\
\text { Distributed } \\
\text { Gamma }\end{array}$ \\
\hline \multicolumn{6}{|l|}{ Outcomes } \\
\hline $\begin{array}{c}\text { Effect of Ceasing Transit on Average Delay } \\
\text { (Homogeneous Driving Delay Model) }\end{array}$ & $6.3 \%$ & $4.7 \%$ & $6.3 \%$ & $6.2 \%$ & $6.2 \%$ \\
\hline $\begin{array}{c}\text { Effect of Ceasing Transit on Average Delay } \\
\text { (Heterogeneous Driving Delay Model) }\end{array}$ & $37.1 \%$ & $28.6 \%$ & $41.0 \%$ & $28.5 \%$ & $33.7 \%$ \\
\hline $\begin{array}{l}\text { Ratio of Heterogeneous Model Effect } \\
\text { to Homogeneous Model Effect }\end{array}$ & 5.9 & 6.1 & 6.5 & 4.6 & 5.4 \\
\hline \multicolumn{6}{|l|}{ Calibration Parameters (Heterogeneous Model) } \\
\hline Share of Population within 2 miles of Rail Line & $30 \%$ & $30 \%$ & $28 \%$ & $22 \%$ & $30 \%$ \\
\hline Average Bus Line Spacing in Residential Areas & 0.5 miles & 0.5 miles & 0.5 miles & 0.7 miles & 0.5 miles \\
\hline
\end{tabular}

Notes: Average delay is chosen to match Parry and Small (2009). Calibration parameter values are the values necessary to equate predicted ridership with observed ridership in the model with heterogeneous driving delays. The effect of ceasing transit under the homogeneous model is smaller in column (2) than other columns because the "captive" riders do not switch to driving when transit service ceases. 
Table A3: Effect of Strike on Traffic Flows over Entire Day

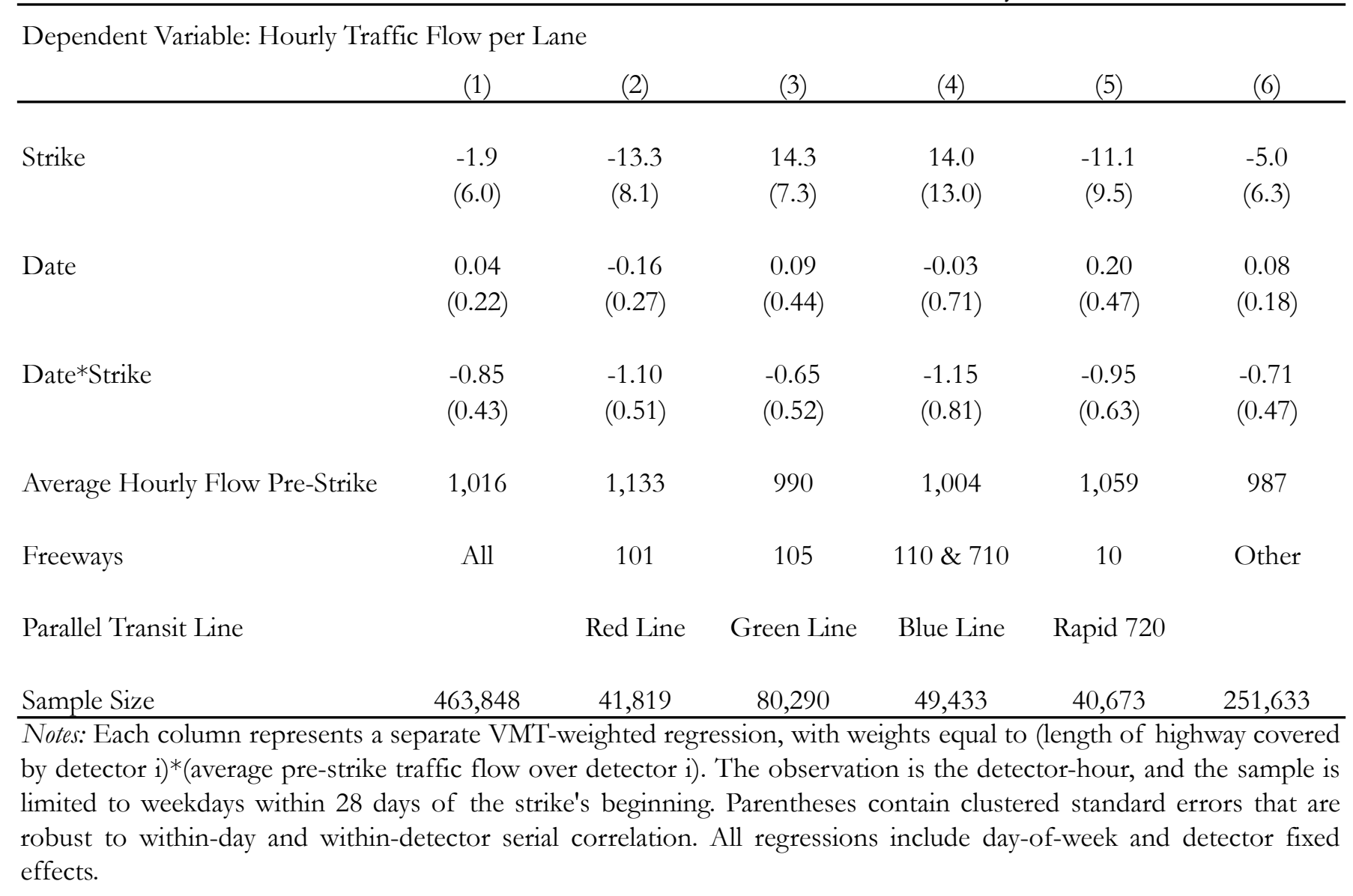

